\title{
مراجعة تحليلية للتوصيات المقترحة في التقارير الدولية للتعامل مع التداعيات
}

\section{الاقتصادية والمالية لجائحة كورونا}

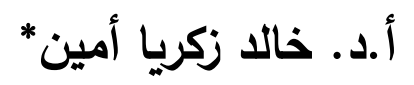

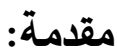

تشهـ كافة دول العالم أزمات عميقة نتيجة لانتشار فيروس كورونا المستجد، الذي اعتبرته منظمة الصحة العالمية وباءً عالمياً نتيجة لسرعة انتشاره في العالم. الأمر الذي دفع العديد من دول العالم لغلق الأنشطة الاقتصادية لاحتواء انتشار الفيروس والحفاظ على حياة مواطنيها. ونتيجة للانتشار السريع لفيروس كورونا المستجد؛ عانت الأنظمة الصحية في دول العالم من الضغط الثديد عليها بما يفوق طاقتها الاستيعابية في غالبية الأحيان، كما أثرت قرارات الغلق الكامل أو الجزئي التي اتخذتها الدول سلباً على الأوضاع الاقتصادية والمالية.

ووفقاً لتوقعات تقرير آفاق الاقتصاد العالمي الصادر عن صندوق النقد الدولي، فإنه من المتوقع أن يشهد الاقتصاد العالمي انكماشاً حاداً بنسبة -3٪ في عام 2020، وهو ما أشار إليه التقرير بأنه أسوأ من الأزمة العالمية في عام 2008. ويتوقع التقرير حدوث تعافي جزئي في النصف الثاني من عام 2021. فقد حدث انخفاض في طلب البترول، وانخفاض في معدلات التجارة الأمر الذي أثر على حركة الصادرات والواردات، بالإضافة إلى سلسلة التوريدات العالمية، كما برزت أيضاً تداعيات فيروس كورونا المستجد على هبوط أسواق المال العالمية، فضلاً عن التأثر السلبي لعدد كبير من القطاعات مثل السياحة، والطيران، والخدمات الترفيهية، بالإضافة إلى ارتفاع معدلات البطالة الأمر الذي أدى إلى تبني الدول مجموعة من الحزم التحفيزية الاقتصادية لمحاولة مواجهة الأثر السلبي سواء من الناحية الاقتصادية أو الاجتماعية الذي أحدثه تفشي هذا الفيروس.

مدير مركز السياسات الاقتصادية الكلية - معهذ التخطيط القومي * م

IMF, "World Economic Outlook", April 2020,

https://www.imf.org/ /media/Files/Publications/WEO/2020/April/English/text.ashx?la=en 
ونتيجة لحالة الإربالك العالمية التي سببها انتشار فيروس كورونا المستجد؛ فقد اتجهت العديد من المنظمات الدولية والجهات المانحة لتقديم توصيات للحكومات بشأن السياسات والإجراءات التي يجب تبنيها للتعامل مع التذاعيات الاقتصادية والمالية لفيروس كورونا المستجد والتخفيف من حدتها. وتتوعت تلك السياسات والإجراءات بين العامة التي تخاطب الاقتصاد ككل، وبين الخاصة التي تخاطب قطاع من القطاعات الاقتصادية أو نشاط بعينه مثل قطاع السياحة أو المشروعات الصغيرة والمتوسطة.

وفى هذا الإطار، تأتي هذه الورقة لاستعراض التوصيات الرئيسية التي وردت في مجموعة من التقارير المتخصصة والصادرة عن بعض المؤسسات الدولية الرئيسية، والتي تخاطب بها الحكومات للتصرف حيال تداعيات أزمة كورونا المستجد، وتتتهي الورقة بنظرة تحليلية حول ما ورد في تلك التوصيات مع بعض الانعكاسات على الدولة المصرية.1

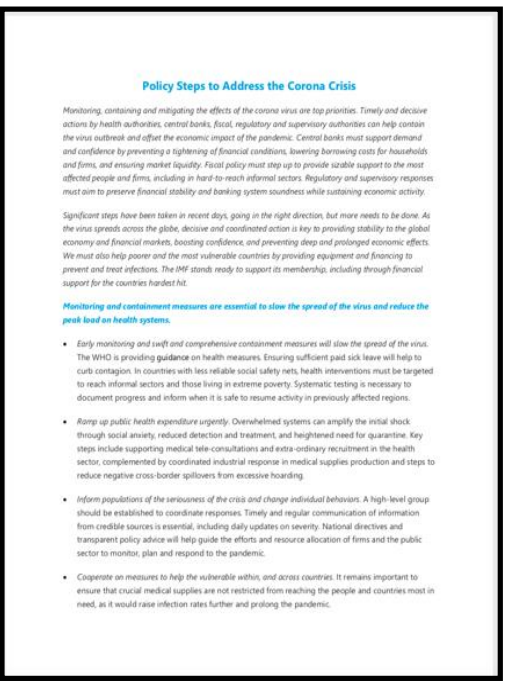
أولاً: عرض لتوصيات التقارير الدولية

1.الخطوات الخاصة بالسياسات المتعلقة بمعالجة أزمة

\section{فيروس كورونا المستجد}

قام صندوق النقد الدولي، في مارس 2020، بإصدار مجموعة من "الخطوات الخاصة بالسياسات المتعلقة بمعالجة أزمة فيروس كورونا المستجد"2، والتي تتضمن مجموعة من الإجراءات سواء المتعلقة بالسياسة الصحية، أو المالية، أو النقدية التي يتعين على الدول اتباعها لمواجهة التداعيات المختلفة لهذا الفيروس. ولقد قسّم صندوق النقد الدولي تلك الخطوات إلى خمس مجموعات رئيسية. وتمثلت المجموعة الأولى في التدابير المتعلقة بمتابعة واحتواء فيروس كورونا 1 تمت مراجعة التقارير الدولية المُختارة بمساهمة علمية فعالة من الأستاذة/ أميرة جمال الدين، باحث أول بالأكاديمية العربية للعلوم والتكنولوجيا والنقل البحري، والأستاذة/ هبة الله هثام، المدرس المساعد بمعهة التخطيط القومي. 2 IMF, "Policy Steps to Address the Corona Crisis", March 2020 ، https://www.google.com/url?sa=t\&rct=j\&q\&=esrc=s\&source=web\&cd=2\&cad=rja\&uact=8\&ved= 2ahUKEwjP8KLOmaDpAhVw3IUKHT7KCakQFjABegQIAxAB\&url=https\%3A\%2F\%2Fwww.imf.or g\%2F \%2Fmedia\%2FFiles\%2FPublications\%2FPP\%2F2020\%2FEnglish\%2FPPEA2020015.ash x\&usg=AOvVaw28iSpd_Lora1SwoETLmkwH 
المستجد وتقليل الضغط على النظام الصحي. وقد اشتملت هذه المجموعة على بعض الإجراءات التي يجب أن تتذذها الدول للعمل على احتواء الفيروس وتباطؤ انتشاره وتقليل الضغط على النظام الصحي منها ضمان القيام بالتتخلات الصحية اللازمة لدعم القطاع غير الرسمي والفقراء، والقيام بالاختبارات الصحية بصورة مستمرة لضمان توثيق التقدم الخاص بانتشار الفيروس، وضمان تقديم إجازات مدفوعة الأجر للعاملين. وتضمنت المجموعة الأولى أيضاً الإجراءات المتعلقة بزيادة الإنفاق العام على الصحة بما في ذلك تعيين عاملين جدد في النظام الصحي، وتعزيز صناعات

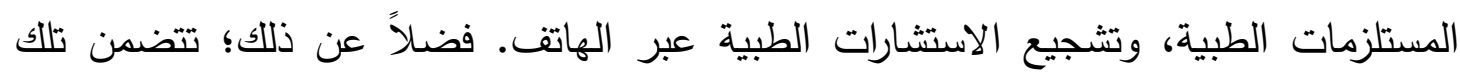
الإجراءات التأثير في سلوكيات المواطنين من خلال الاتصال الجيد عن طريق تقديم معلومات يومية محدثة من مصادر موثوقة، ونشر المعلومات المتعلقة بتوجهات الدولة بشأن التعامل مع الفيروس. كما اشتملت هذه الإجراءات على تعزيز تقديم الإمدادات الطبية اللازمة للأفراد والدول

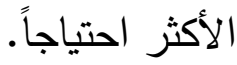

أما المجموعة الثانية فتتمثل في التدابير المتعلقة بدعم البنوك المركزية لجانب الطلب لتعزيز الثقة وتسهيل الظروف المالية وضمان السيولة في الأسواق المالية المحلية والدولية لدعم السوق، والتسهيل النقدي لاعم الطلب وخفض تكاليف الاقتراض على الأسر والثركات، بالإضافة إلى تعزيز التتسيق مع البنوك المركزية لدول مجموعة السبعة للعمل على دعم استقرار الاقتصاد العالمي والأسواق المالية، وذلك لتقليل الضغط على الأسواق المالية العالمية، بالإضافة إلى تشجيع البنوك المركزية على تبادل العملات وفق اتفاقات مرنة بخطوط إئتمان. كما تتضمن هذه الإجراءات تقديم التوصيات للأسواق الناشئة والنامية فيما يتعلق بالتعامل مع الصدمات المتوقعة في أسعار السلع، والتراجع في تدفقات رأس المال.

وتتمثل المجموعة الثالثة في التدابير المتعلقة بدعم السياسة المالية التي تدعم الأفراد والثركات المتضررة وتعمل على تحفيز الطلب. وتتضمن المجموعة الثالثة مجموعة من الإجراءات منها دعم الأجور للأعمال التي توقفت نتيجة لانتشار الفيروس لمنع الإفلاس وتسريح العاملين، بالإضافة إلى التحويلات النقدية للأسر ذات الدخل المحدود للحفاظ على الحد الأدنى من مستوى المعيشة، فضلاً عن تعزيز التخفيضات الضربيية. كما تضمنت تلك المجموعة تقديم حزم مالية تحفيزية 
واسعة النطاق، بالإضافة إلى زيادة الاستجابة المالية من قبل دول مجموعة السبعة وتعزيز التعاون والتنسيق فيما يتعلق بتقديم حزم تحفيزية مالية عالمية.

واشتملت المجموعة الرابعة على "الاستجابة التنظيمية للحفاظ على التوازن بين الاستقرار المالي، وسلامة النظام المصرفي، واستدامة النشاط الاقتصادي" والتي تضمنت تثجيع البنوك على اتباع نهج أكثر مرونة ضمن القواعد القائمة والقيام بإعادة المفاوضات فيما يتعلق بالشروط الخاصة

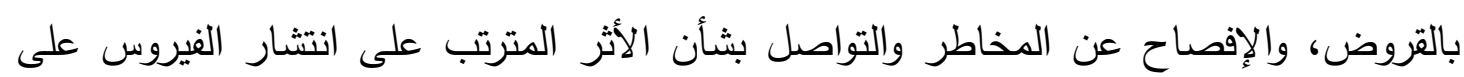
ضمان انتظام السوق، بالإضافة إلى تدابير الدعم الإضافية المتعلقة بتقديم الدعم والإعفاء الضريبي لصغار المقترضين، ودعم البنوك من خلال برامج ضمانات الائتمان وشراء الأصول.

واشتملت المجموعة الخامسة على "التعاون والتسيق العالمي" والتي تضمنت تعزيز السياسات الوقائية من قبل دول مجموعة السبعة والاقتصادات الكبرى لاحتواء معدلات الإصابة بالفيروس، ودعم تدفق الإددادات الطبية وغيرها. كما اشتملت هذه المجموعة على الإجراءات المتعلقة بتقوية النظم الإدارية لتعزيز قدرتها على الاستجابة، بالإضافة إلى استعداد صندوق النقد الدولي إلى تعبئة

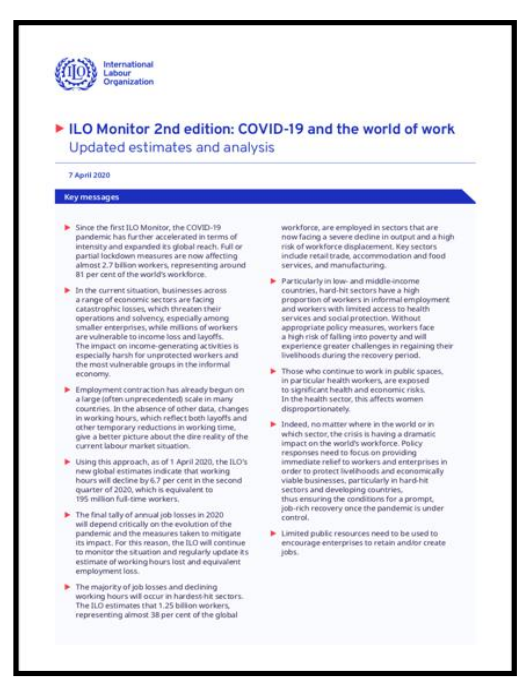
ترليون دولار لمساعدة الدول على تخطي التداعيات الاقتصادية والمالية والاجتماعية لفيروس كورونا المستجد.

\section{2 - فيروس كورونا المستجد وعالم العمل}

أصدرت منظمة العمل الدولية في أبريل 2020، الإصدار الثاني من متابعات تداعيات انتثار الفيروس تحت عنوان "فيروس كورونا المستجد وعالم العمل" . وعرض التقرير

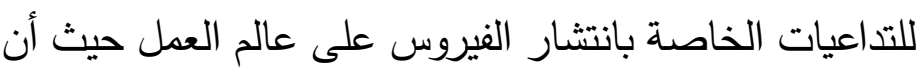
الغلق الجزئي للأنشطة الاقتصادية أثر على حوالي 2.7 مليار عامل يمثلون حوالي 81٪ من قوة

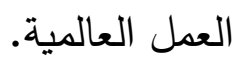

1 ILO, "ILO Monitor: COVID-19 and the World of Work", 7 April 2020,

https://www.ilo.org/wcmsp5/groups/public/@dgreports/@dcomm/documents/briefingnote/wcm s_740877.pdf 
وأكد التقرير على أن الشركات العاملة في مختلف القطاعات تواجه خسارة كبيرة مما يهدد استمرارها ويعرضها لخطر الإفلاس، وخاصة الثركات الصغيرة التي يكون فيها العاملين معرضين لخسارة عمهم. ويعد الأثر السلبي لانتشار الفيروس كبيراً خاصة على العمالة غير المؤمن عليها والمجموعات العاملة في الاقتصاد غير الرسمي. وأشار التقرير إلى أن تقليص العمالة بدأ على لهي

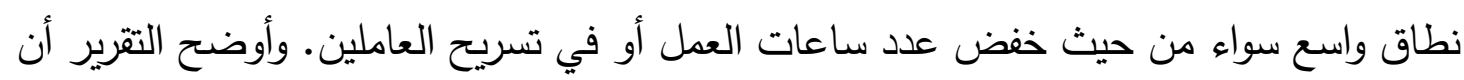
تقديرات منظمة العمل الدولية تشير إلى أنه اعتباراً من الأول من أبريل 2020 ستخفض ساعات العمل بحوالي 6.7٪ في الربع الثاني من عام 2020 وهو ما يعادل 195 مليون عامل بدوام كامل. (- n

وأشار التقرير إلى أن النسبة العظمى من فقدان الوظائف ستكون في القطاعات الأكثر تأثراً بانتشار الفيروس؛ فتشير تقديرات منظمة العمل الدولية أن حوالي 1.25 مليار عامل يمثلون نحو 38 من قوة العمل العالمية يعملون في القطاعات الأكثر تأثراً بالأزمة وهم الأكثر عرضة لفقدان وظائفهر، وتتمثل تلك القطاعات في تجارة التجزئة، والخدمات الغذائية والتصنيع. أما بالنسبة للدول المنخفضة والمتوسطة الدخل؛ فإن القطاعات المتضررة لديها نسبة كبيرة من العاملين في القطاع غير الرسمي والذين يصعب حصولهج على الخدمات الصحية وخدمات الحماية الاجتماعية. وبالتالي؛ بدون وجود إجراءات جيدة للتعامل مع التداعيات الخاصة بانتشار الفيروس، سيواجه هؤلاء العاملين خطر الفقر وصعوبة استعادة أعمالهم خلال فترة استعادة النشاط الاقتصادي بعد الأزمة.

وأكدت منظمة العمل الدولية أن الوضع النهائي الخاص بالخسائر الوظيفية حول العالم سيتم تحديده وفقاً لمدى انتشار فيروس كورونا المستجد والإجراءات التي تم اتخاذها للتخفيف من آثاره. وبالتالي؛ يجب أن تركز السياسات والإجراءات التي تتخذها الدول على تقديم الدعم للعاملين والثركات لحماية سبل العيش، والثركات ذات الجدوى الاقتصادية وخاصة في القطاعات المتضررة.

ومن ثمّ؛ قدمت منظمة العمل الدولية إطاراً للسياسات يتضمن أربعة محاور أساسية لمحاربة فيروس كورونا المستجد وفقاً لمعايير العمل الدولية. ويتمثل المحور الأول في تحفيز الاقتصاد والتوظيف، ويركز على تعزيز السياسة المالية والنقدية، وتقديم الدعم لقطاعات بعينها بما في ذلك قطاع 
الصحة. أما المحور الثاني فيركز على دعم الشركات والوظائف والدخول بما في ذلك من تعزيز الحماية الاجتماعية للجميع، وتتفيذ إجراءات للحفاظ على العمالة، وتقديم الدعم المالي والإعفاءات الضريبية للشركات. أما المحور الثالث فيعنى بحماية العاملين في أماكن العمل ويضم تقوية إجراءات السلامة والصحة المهنية، وتطبيق ترتيبات مختلفة للعمل مثل العمل عن بعد، ومنع التمييز والاستبعاد في العمل، وإتاحة الخدمات الصحية للجميع، وزيادة الحصول على إجازات

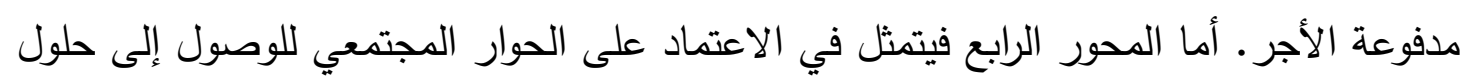

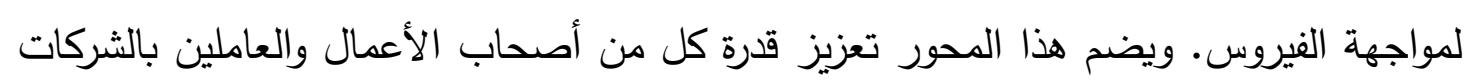
والمؤسسات، وقدرة الحكومة بالإضافة إلى تعزيز الحوار المجتمعي للوصول إلى حلول لمواجهة تداعيات فيروس كورونا المستجد.

وأشار التقرير إلى أن هنالك مجموعة من الإجراءات الأخرى التي يجب أن يتم وضعها في الاعتبار بجانب المحاور المشار إليها. وتتضمن تلك الإجراءات الدعم الفوري للأفراد والقطاعات الأكثر تضرراً، وخاصة العاملين في القطاع غير الرسمي، بالإضافة إلى ضمان استخدام الموارد المالية العامة لاعم التوظيف. ومن الممكن أن تقوم الثركات بتقديم الدعم المالي وغير المالي للحفاظ

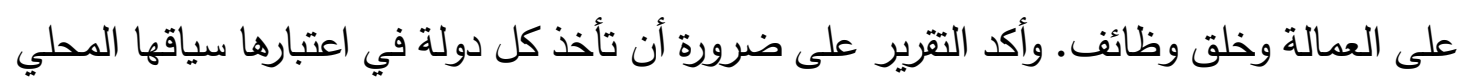

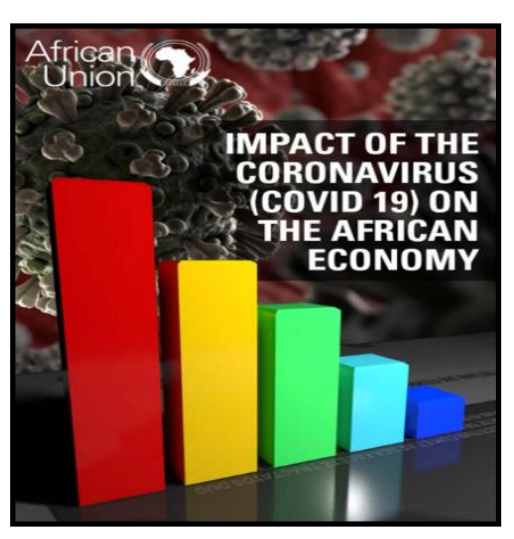
والهيكل الاقتصادي الخاص بها عند اتخاذ أية إجراءات تتعلق بالتعامل مع تداعيات فيروس كورونا المستجد. 3. أثر فيروس كورونا المستجد على الاقتصاد الأفريقي أصدر الاتحاد الأفريقي تقريراً في أبريل 2020 حول "أثر فيروس

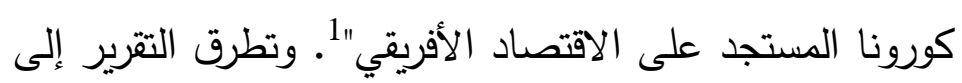
السياق العالمي للاقتصاد في ظل انتشار فيروس كورونا المستجد بما في ذلك من الأثر المتوقع على النمو الاقتصادي العالمي وبعض القطاعات المتضررة مثل قطاع الطيران الددني، بالإضافة إلى إلقاء الضوء على الحزم التحفيزية التي قدمتها بعض المنظمات الدولية ودول العالم. وفي

1 African Union, "Impact of the Coronavirus (COVID-19) on the African Economy", 2020, https://www.tralac.org/documents/resources/covid-19/3218-impact-of-the-coronaviruscovid-19-on-the-african-economy-african-union-report-april-2020/file.html 
تحليله لأثر انتشار الفيروس على الاقتصاد الأفريقي استخدم التقرير سيناريوهين رئيسيين اعتمد كل منهما على فترة مختلفة متوقعة لانتشار الفيروس.

وأوضح التقرير أن هناك العديد من القطاعات التي تأثرت سلباً على المستوى الأفريقي مثل قطاعات السياحة، والنقل، والبترول. فقبل أزمة كورونا، كان من المتوقع أن يصل معدل النمو في أفريقيا في عام 2020 إلى 3.4٪؛ إلا أنه في ظل الأثر السلبي على القطاعات المختلفة فمن المستحيل الوصول إلى مثل هذه المعدلات. حيث توقع التقرير أن يصل معدل النمو في أفريقيا وفق السيناريو

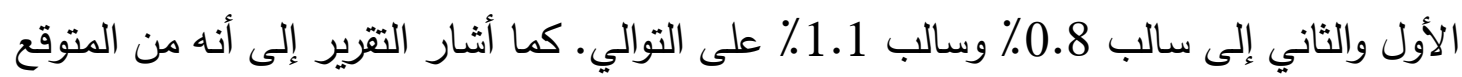
أن يخسر كل من قطاعي السياحة والسفر في أفريقيا حوالي 50 مليار دولار وعلى الأقل 2 مليون وظيفة مباشرة وغير مباشرة. وأشار التقرير إلى أن انتشار الفيروس سيؤدي إلى خفض الواردات وعجز في السلع الأساسية الواردة من الصين في الأساس.

وقدّم التقرير مجموعة من التوصيات لدول الاتحاد الأفريقي للتعامل مع التداعيات الاقتصادية

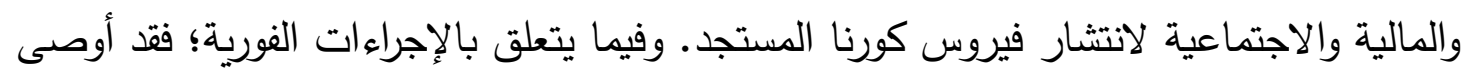
التقرير بضرورة التحقق بصورة منظمة من الحالات المشتبه فيها لضمان الكشف المبكر عن العدوى والعمل على تتبع الحالات قدر الإمكان، وتطبيق الحجر الصحي على المصابين بالفيروس لمنع الانتشار ـ كما أوصى التقرير بضرورة الإبلاغ عن الإحصاءات الصحية والعمل مع منظمة الصحة ولطئي العالمية والمراكز الأفريقية لمكافحة الأمراض والوقاية مع العمل على ضمان متابعة الأزمة بشفافية لتعزيز ثقة المواطنين الأفريقيين.

كما حتّّ التقرير الدول الأفريقية على ضرورة مراجعة موازناتها وإعطاء الأولوية في الإنفاق لنظم الرعاية الصحية بما في ذلك البنية التحتية وشراء المنتجات الدوائية والطبية، والمعدات والمواد المطلوبة لمكافحة انتشار الفيروس. فضلاً عن ذلك؛ اشتملت الإجراءات الفورية التي أوصى بها التقرير على إنشاء صندوق للطوارئ يعمل على تعزيز الحماية الاجتماعية واستهداف العاملين في القطاع غير الرسمي الذين لا يتمتعون بالحماية الاجتماعية والذين تأثروا بشدة من انتشار الفيروس، بالإضافة إلى زيادة التمويل المتعلق بالبحوث الطبية. 
وشجّع التقرير الدول على العمل مع الحكومات والمجتمعات المحلية ورواد الأعمال لإيجاد حلول للوقاية والعلاج وفق السياق المحلي، وتسهيل الوصول إلى المعلومات وتتديم الدعم القانوني لتسهيل تتفيذ الحلول المبتكرة. بالإضافة إلى تعزيز مشاركة المعلومات والبيانات المختلفة والحد من الترويج لمعلومات المغلوطة.

وأوصى التقرير بالعمل على دعم الإنفاق من خلال الاقتراض لصناديق الطوارئ، وذلك نظراً إلى أن سعر الفائدة منخفض حالياً، وأن كثير من الدول ستتعرض إلى دنى عجز في الموازنة نتيجة

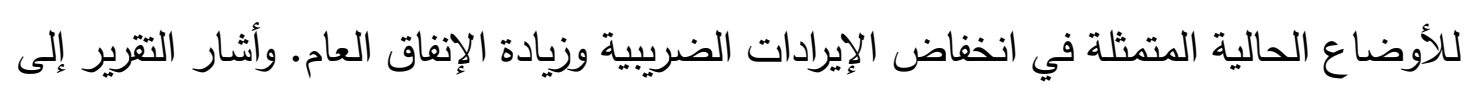
ضرورة اتخاذ التدابير الاقتصادية والمالية اللازمة لتقديم الدعم للشركات الصغيرة والمتوسطة والأفراد. وطالب التقرير البنوك المركزية في الدول الأفريقية بخفض سعر الفائدة لتمكين الثركات من الحصول على قروض بتكلفة منخفضة، بالإضافة إلى تزويد البنوك التجارية بالسيولة اللازمة لاعم الأنشطة التجارية. وتضدنت التوصيات إلغاء أو تأجيل الفائدة على الددفوعات بكروت الائتمان وسندات الشركات، بالإضافة إلى إعداد حزم اقتصادية تحفيزية لتقليل أثر انتثار الفيروس على الاقتصاد الوطني،

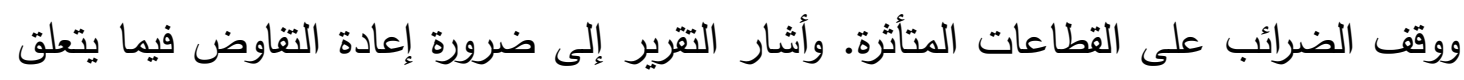
بشروط وخطط سداد الديون الخارجية بما في ذلك تعليق مدفوعات أسعار الفائدة في وقت الأزمة. كما قّم التقرير مجموعة من التوصيات تتعلق بالإجراءات الفورية لمفوضية الاتحاد الأفريقي منها قيادة المفاوضات لإلغاء الديون الخارجية الأفريقية والتي يبلغ مجموعها 236 مليار دولار أمريكي، وتعزيز التعاون والتضامن والتتسيق ونقل الخبرات بين الدول الأعضاء في الاتحاد الأفريقي، وإعداد آلية للتنسيق لمراقبة انتشار الفيروس وتحديد السياسات التي تم اتخاذها من قبل الدول الأعضاء لمواجهة تداعيات انتشار الفيروس.

أما فيما يتعلق بالتعامل مع التداعيات المتعلقة بانتشار الفيروس على الددى المتوسط، أي بعد انحساره، فقد قدّم التقرير مجموعة من التوصيات للدول الأفريقية تضمنت ضرورة تتويع وتحويل اقتصادات الدول الأفريقية من خلال تعزيز القدرات الإنتاجية للقطاع الخاص الأفريقي للقيام بتحويل المواد الخام محلياً، بالإضافة إلى زيادة الإنتاج الزراعي لتحسين سلاسل القيمة الغذائية. واشتملت 
التوصيات على الانتهاء من التوقيع والتصديق على هيئة الدواء الأفريقي، والعمل على بناء شراكات بين القطاعين العام والخاص لإنتاج المنتجات الدوائية والطبية، وتعزيز الأساليب المبتكرة للإنفاق على الصحة، وتعبئة الموارد اللازمة لقطاع الصحة، والاستفادة من الثورة الرقمية لتحويل الاقتصاد الأفريقي بما يحقق الأجندة الأفريقية 2063، والإسراع في تتفيذ منطقة التجارة الحرة القارية. وبالنسبة للتوصيات المقدمة لمفوضية الاتحاد الأفريقي على المدى المتوسط؛ فقد حث التقرير المفوضية على العمل على تعزيز النظم الصحية ونظم الحماية الاجتماعية في الدول الأفريقية، ومواصلة تعزيز التحول الإنتاجي وتشجيع القطاع الخاص على الصناعة المحلية، وقيادة مفاوضات لاعم الدول الأعضاء بمبالغ مالية من المؤسسات الدولية لمساعدتهم على مواجهة الأزمة، وضمان وجود استجابة عالمية للتنسيق فيما يتعلق باستمرار التدفقات المالية بما في ذللك الاستثمار الأجنبي المباشر، وتحويلات المواطنين في الخارج، والمساعدات الإنمائية الرسمية. كما أوصى التقرير المفوضية بتجهيز الدول الأفريقية للاستفادة الكاملة من التغيرات التي من المتوقع حدوثها في أعقاب أزمة انتشار فيروس كورونا المستجد، حيث دن المحتمل أن تقوم الاقتصادات الكبرى بتتويع مراكز إنتاجها من خلال التحول إلى الاستفادة من مناطق أخرى، الأمر الذي يتطلب تزويد الشباب بالمهارات اللازمة لجذب الشركات متعددة الجنسيات والجهات الفاعلة التجارية العالمية الأخرى.

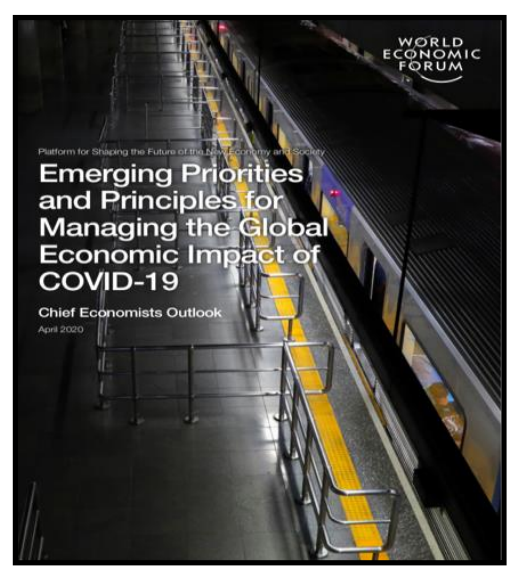
4.الأولويات والمبادئ الملحة لإدارة الأثر الاقتصادي العالمي لفيروس كورونا المستجد

قام المنتدى الاقتصادي العالمي في أبريل 2020 بإصدار تقرير تحت عنوان "الأولويات والمبادئ الملحة لإدارة الأثر الاقتصادي العالمي لفيروس كورونا المستجد" •. واعتمد التقرير على استقصاء ومجموعة من الحوارات الافتراضية بين أعضاء مجتمع كبار الاقتصاديين التابع للمنتدى، بالإضافة إلى مجموعة من القيادات الأخرى بهدف تقديم

${ }^{1}$ World Economic Forum, “Emerging Priorities and Principles for Managing the Global Economic Impact of COVID-19", April 2020, http://www3.weforum.org/docs/WEF_Chief_Economists_Outlook_April_2020.pdf 
تقييم مبئي للسياسات التي تم تنفيذها من قبل الحكومات المختلفة في ظل مواجهة تداعيات فيروس كورونا المستجد، والتحديات التي تواجه تتفيذ تلك السياسات وأثرها في المستتبل.

وخلُص التقرير إلى مجموعة من التوصيات التي تمثل المبادئ الأساسية والسياسات التي يجب على الدول أن تضعها في الاعتبار كأولويات رئيسية في التعامل مع أزمة انتثار فيروس كورونا

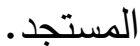

واعتبر التقرير السياسات المتعلقة بالقطاع الصحي هي الأولوية الأولى والرئيسية التي يجب أن تضعها الدول على رأس سياسات الاستجابة لضمان الحفاظ على الأرواح ودعم عملية إنتاج علاج ومصل خلال الأشهر القادمة. وبالإضافة للسياسات المتعلقة بالقطاع الصحي؛ ألقى التقرير الضوء على أربعة قضايا أخرى يجب أن تكون في محور اهتمام صناع السياسات حتى تمكنهم من التعافي بعد الأزمة. وتتمثل القضية الأولى في دفع المساعدات للشركات بصورة سريعة، حيث على الرغم من أن أغلب الدول قامت بتقديم العديد من أوجه الدعم والمساعدات للمشروعات الصغيرة والمتوسطة؛ إلا أن الفيصل الرئيسي يكمن في سرعة صرف هذه المساعدات لتلك الثركات حتى لا يتعرضوا لخطر الإفلاس نتيجة في التأخر في الصرف. ففي العديد من الحالات؛ يستهلك الحصول على المساعدات المالية التي تقدمها الحكومة وقتاً طويلاً مما يمثل أزمة للشركات الصغيرة والمتوسطة. وبالتالي؛ يجب على الحكومات إيجاد حلول سريعة للتعامل مع مثل تلك المشكلات. وأشار التقرير إلى التجربة الصينية التي استفادت من التعامل السابق مع انتشار فيروس "سارس" من خلال الاستثمار في الاقتصاد الرقمي المجزز لتعبئة رأس المال الخاص، وتقديم الدعم للمشروعات الصغيرة والمتوسطة من خلال التمويل عبر الإنترنت "Internet Financing"، وذلك باستخدام منصات التكنولوجيا المالية "Fintech" التي تستخدم أنظمة التصنيف الايتماني التي التيرلي تعتمد على البيانات الضخمة، ونظم المراقبة، والوصول لأكبر قدر من المناطق الجغرافية. ومن ثمّ ساهم التمويل الرقمي الذي استثرت فيه الحكومة الصينية كأداة رئيسية في القروض الطارئة وخاصة للمشروعات الصغيرة والمتوسطة في مواجهة الأزمة الحالية الخاصة بفيروس كورونا 
أما القضية الثانية فتتمثل في دعم الأسر والعاملين الأكثر احتياجاً، حيث ثبت أن شبكات الأمان الاجتماعي الموجودة لم تكن كافية للتعامل مع الأزمة الحالية وتغطية كافة الأسر والعاملين الأكثر احتياجاً. فتتأثر مجموعات كبيرة من العاملين بصورة سلبية بسبب التداعيات الاقتصادية للأزمة، وخاصة العاملين الأكثر عرضة للخطر وهم الذين يعتمد عمهم على التفاعل المادي (وجهاً لوجه) ولا يستطيعون العمل من المنزل، مثل العاملين في الرعاية الصحية، وقطاع الغذاء، والخدمات اللوجيستية. وبالتالي؛ فإن حماية أكبر عدد مدكن من الوظائف سيسهم بشكل كبير في تعافي الاقتصاد بعد الأزمة، فقد أقدمت العديد من الدول الأوروبية على تقديم خطط لدعم العاملين للعمل وفق عدد ساعات عمل منخفضة، ووضع شروط على شركات القطاع الخاص -في حالة حصولها على الدعم - لعدم تسريح العاملين. وأوضح التقرير أنه نتيجة لعدم استيعاب شبكات الأمان الاجتماعي الحالية للمتضررين من الأزمة الحالية؛ قامت العديد من الدول بتوسيع التغطية الخاصة ببرامج البطالة لتقوم بتغطية عدد أكبر من العاملين. كما أشار التقرير إلى أنه من الممكن أن تلجأ الدول إلى وقف الديون للأسر التي لديها قروض عقارية كأداة سياسية لتوفير مساحة مالية إضافية. وأوصى التقرير بتعزيز المدفوعات الرقمية للمساهمة في تعزيز التغطية الخاصة ببرامج الدعم المختلفة.

أما القضية الثالثة التي عني بها التقرير فهي قضية توفير الدعم المالي للدول منخفضة ومتوسطة الدخل، حيث أن انتشار الفيروس يتطلب التضامن مع الدول منخفضة ومتوسطة الدخل وتقديم

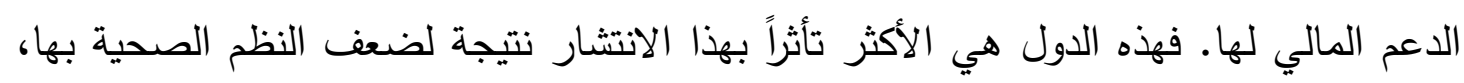
وشبكات الأمان الاجتماعي. وعلى الرغم من إعلان صندوق النقد الدولي، والبنك الدولي عن برامج للإقراض؛ إلا أنه يجب الوضع في الاعتبار إعداد برامج مكملة تتضمن وقف الديون وتوفير دعم إضافي من الدول المتقدمة.

وتتمثل القضية الرابعة في توسيع أولويات السياسة العالمية التقليدية، حيث أنه على الرغم من أن جدول أعمال تغير المناخ والتحول الأخضر أصبح بالفعل مسألة حاسمة في النقاشات العالمية وإعداد السياسات الوطنية، إلا أن الأزمة الحالية كثفت عن قصور شديد في العديد من القضايا والقطاعات منها الرعاية الصحية، والأجور، وأنظمة شبكات الأمان الاجتماعي، وعدم المساواة. وحتى الآن؛ لا تُظهر أولويات السياسة العالمية تغيراً كبيراً في الاتجاه، فيرى البعض أن يتم توجيه 
الاهتمام للقطاع الصحي، بينما يرى الآخرون إيلاء الأولوية إلى حماية أكبر عدد ممكن من

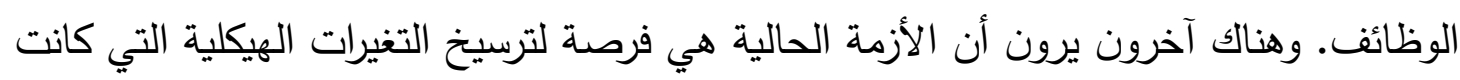

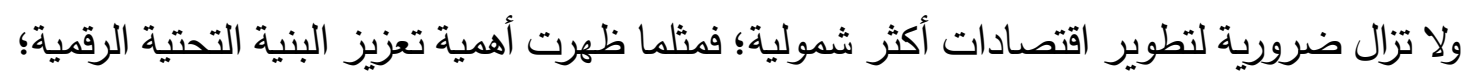
فلا بد للحكومات أن تعمل على ضخ المزيد من الاستثمارات الخضراء، والثراكة بين القطاعين

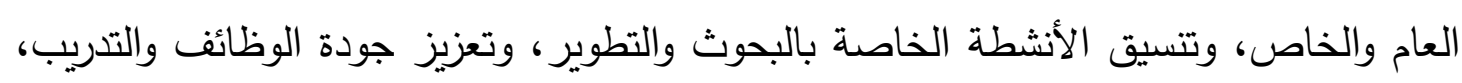
والعمل على تحسين الصناعات بما يعزز من الحد من انبعاثات الكربون.

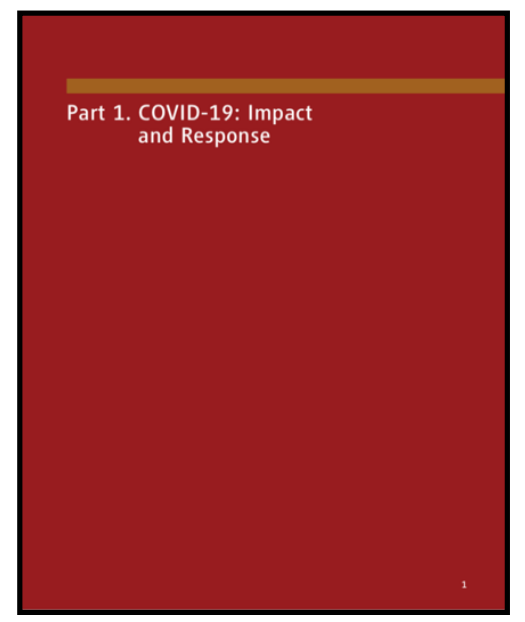

\section{5. فيروس كورونا المستجد: الأثر والاستجابة}

أصدر مكتب منطقة شرق آسيا والمحيط الهادي التابع للبنك الدولي تقريراً حول "فيروس كورونا المستجد: الأثر والاستجابة"، وذلك في أبريل 2020. وتتاول التقرير أثر الفيروس على الاقتصاد العالمي والتوقعات المتعلقة بالنمو،

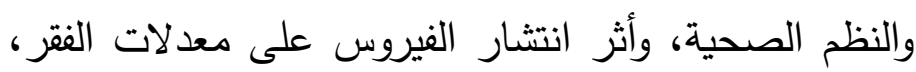
بالإضافة إلى أثره على الصين. وانتهى التقرير بمجموعة من التوصيات المتمثلة في عدد من الإجراءات المتعلقة بالسياسات التي يجب أن تتخذها الدول لمواجهة تداعيات انتشار الفيروس.

وأوصى التقرير الدول بضرورة الاستثمار في جاهزية النظم من خلال إعداد سياسات وقائية طويلة المدى، حيث يعتمد مستوى الوقاية على درجة جاهزية النظام الصحي ومستوى هشاشـة المواطنين، وأشار التقرير إلى ضرورة أن تأخذ تلك السياسات في الاعتبار الروابط بين صحة الحيوان وسلامة

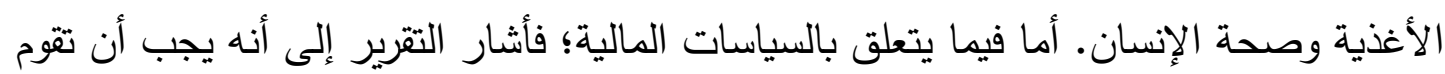

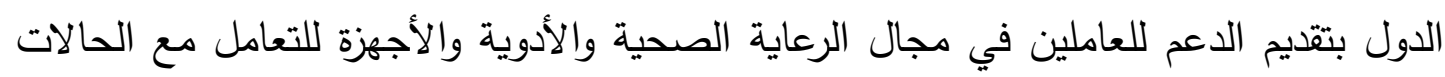
الخاصة بفيروس كورونا المستجد، بالإضافة إلى تخصيص الموارد اللازمة لتوعية المواطنين،

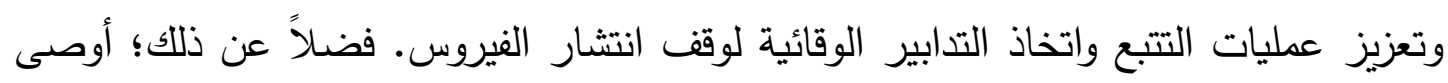

${ }^{1}$ World Bank East Asia and Pacific, "Part1: COVID-19 Impact and Response", April 2020, https://openknowledge.worldbank.org/bitstream/handle/10986/33477/211565-ch01.pdf 
التقرير بضرورة حماية الأفراد والثركات من الآثار الاقتصادية لانتشار الفيروس من خلال توفير التحويلات النقدية، وإعانات الأجور ، وتخفيضات الضرائب للأفراد والشركات المتضررة.

وبالنسبة للسياسات النقدية؛ فقد أشار التقرير إلى ضرورة أن تقوم البنوك المركزية بتخفيف القيود المالية من خلال خفض أسعار الفائدة وتوفير السيولة النقدية الكافية للبنوك والمؤسسات المالية غير المصرفية، والعمل على تخفيف شروط الائمان وتوفير الدعم خاصة المشروعات الصغيرة والمتوسطة المتضررة من الفيروس. وفيما يتعلق باستقرار النظم المالية؛ فأشار التقرير إلى ضرورة عمل الهيئات الحكومية مع البنوك والمؤسسات المالية للتأكد من تكيفها السريع لتخفيف الآثار السلبية للصدمة، مع وضع شفافية النظام المالي في الاعتبار .

وأوصى التقرير بضرورة فتح التجارة بين الدول؛ حيث أنه نتيجة لانتشار الفيروس قامت العديد من الدول بفرض قيود صارمة على المنتجات الطبية مما له أثر بالغ الضرر على كثير من

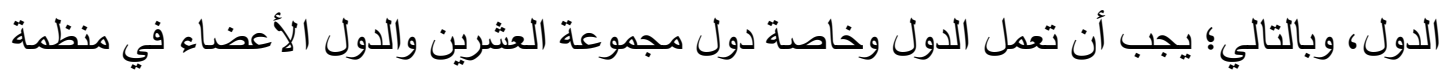
التجارة العالمية على عدم تقييد صادرات المنتجات الطبية ذات الصلة بفيروس كورونا المستجد. وفيما يتعلق بالسياسات الخاصة بالحد من الفقر ؛ فقد قدّم التقرير مجموعة من الإجراءات التي

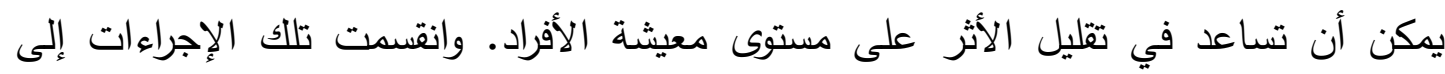
الإجراءات المتعلقة باحتواء انتثار الفيروس وتخفيف أثره على الصحة مثل تقديم الإجازات الصحية مدفوعة الأجر، وتوفير الاختبارات والعلاج المدعم أو المجاني. والإجراءات الدتعلقة بدعم الفقراء والعاملين الجدد المتأثرين بغلق النشاط الاقتصادي مثل توسيع شبكات الأمان والتأمين الاجتماعي من خلال تقديم الدعم النقدي والعيني، بالإضافة إلى تقديم الدعم للشركات للحفاظ على العاملين. وبالنسبة للإجراءات قصيرة المدى التي يجب اتخاذها لتجنب الآثار طويلة المدى للأزمة فتتمثل في تقديم الوجبات الدرسية للأسر التي تعتمد عليها، حيث من المكن تقديم المبالغ الخاصة بتلك الوجبات للأطفال رغم توقف الدراسة للحفاظ على رأس المال البشري على الددى الطويل. أما فيما يتعلق بالإجراءات الخاصة بدعم اندماج العاملين بعد انتهاء الأزمة من خلال تحسين

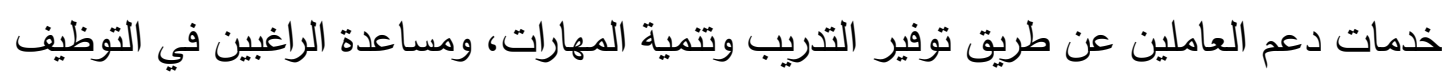

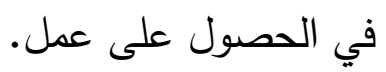




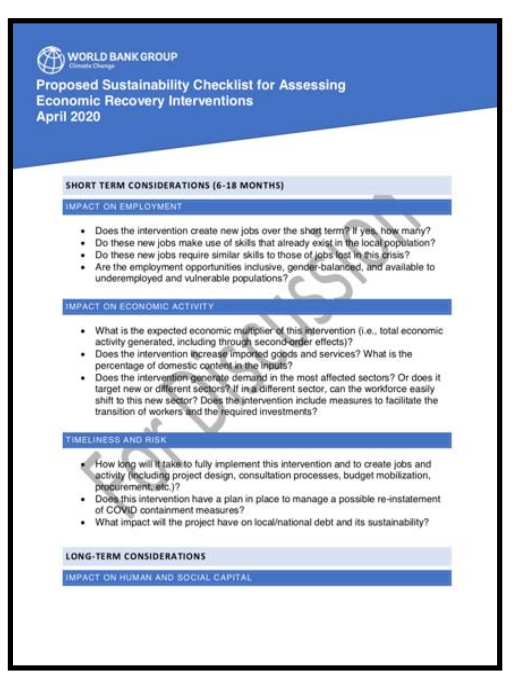

6. قائمة مقترحة لضمان الاستدامة من خلال تقييم تدخلات التعافي الاقتصادي

أصدر البنك الدولي في أبريل 2020 قائمة تضم مجموعة من القضايا بعنوان "قائمة مقترحة لضمان الاستدامة من خلال تقييم تدخلات التعافي الاقتصادي" . وعلى الرغم من أن هذه

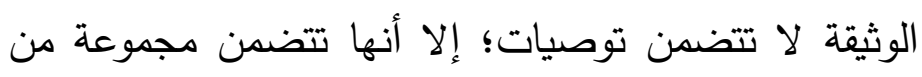
الأسئلة التي يجب أن تأخذها الدول في الاعتبار لضمان استدامة تدخلاتها المتعلقة بمواجهة تداعيات فيروس كورونا المستجد.

وانقسمت القائمة إلى الاعتبارات قصيرة المدى، والاعتبارات طويلة المدى. وتضمنت الاعتبارات قصيرة المدى (6 - 18 شهر) مجموعة من القضايا المختلفة مثل الاعتبارات الخاصة بالأثر على الى التى التوظيف والتي تتضمن إلى أي مدى تساهم التدخلات التي اتخذتها الدولة في خلق فرص عمل جديدة على المدى القصير، ومدى شمولية فرص العمل وتوازنها بين الجنسين، كما تطرق التقرير للاعتبارات الخاصة بالأنشطة الاقتصادية التي تضمنت إلى أي مدى ساهدت التدخلات في زيادة السلع المستوردة ومدى استخدام المكونات المحلية في السلع المختلفة، وهل التدخلات تقوم بتوليد الطلب في القطاعات الأكثر تضرراً.

أما بالنسبة للاعتبارات طويلة المدى فتركز القائمة على الأثر على رأس المال البشري والاجتماعي التي تتضمن إلى أي مدى تركز التدخلات على خلق فرص عمل لائق، وبناء المهارات، وتساهم في مشاركة المرأة في فرص العمل، وتحسين الصحة العامة، والإنتاجية المحلية، وتعزيز نظم الحماية الاجتماعية. كما تشمل القائمة الأثر على التكنولوجيا من خلال مدى مساهمة التخخلات

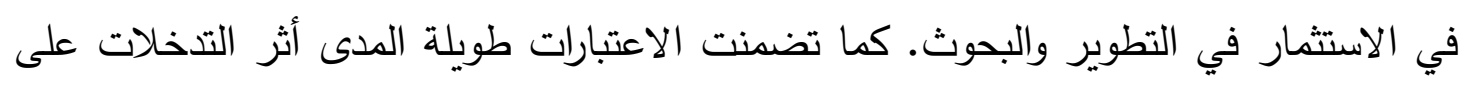
غلق الفجوة في الوصول لخدمات البنية التحتية الرئيسية، وتحسين الإنتاجية الاقتصادية المحلية

${ }^{1}$ World Bank, "Proposed Sustainability Checklist for Assessing Economic Recovery Interventions", April 2020,

http://pubdocs.worldbank.org/en/223671586803837686/Sustainability-Checklist-forAssessing-Economic-Recovery-Investments-April-2020.pdf 
من خلال الوصول لخدمات البنية التحتية. بالإضافة إلى مدى معالجة التحخلات لإخفاقات السوق، وتحسين المرونة والصمود للنظم الاقتصادية والاجتماعية في مواجهة الأزمات، وتحسين قدرة المجتمع على التكيف مع الأزمات.

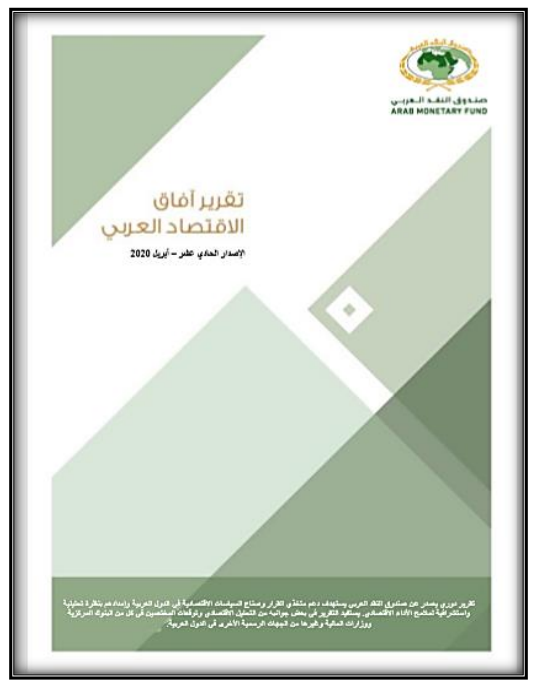

7.تقرير آفاق الاقتصاد العربي

أصدر صندوق النقد العربي في أبريل 2020 الإصدار الحادي عشر من تقرير آفاق الاقتصاد العربي، ويعد صندوق النقد العربي مؤسسة مالية عربية إقليمية تأسست عام 1976، وبدأت في ممارسة نشاطها عام 1977، ويبلغ عدد الدول الأعضاء فيها 22 دولة عربية. ويهذف الصندوق إلى تصحيح الاختلال في موازين مدفوعات الدول الأعضاء، والعمل على إزالة القيود على المدفوعات الجارية بين الدول الأعضاء، وتطوير الأسواق المالية

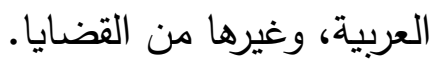

ولقد اعتمد تقرير آفاق الاقتصاد العربي على أربعة افتراضات أساسية1. يتمثل الأول منها في أن امتداد الأثر الاقتصادي لفيروس كورونا، سيؤدى إلى تأثر الاقتصاد العالمي والاقتصادات العربية بصدمات جانبي العرض والطلب وتزايد مستويات عدم اليقين وتراجع مستويات ثقة المستثمرين والمستهلكين حتى النصف الأول من عام 2020، مع افتراض عدم حدوث حالات إغلاق، واسعة النطاق عالميا. فمن ناحية، ستودي إجراءات الحجر الصحي والمرض والمشاعر السلبية للمستهلكين والأعمال إلى خفض الطلب الكلي. ومن ناحية أخرى، سيؤدي إغلاق بعض المصانع وتعطيل سلاسل التوريد إلى اختناقات في الإمدادات تؤثر على مستويات العرض.

أما الافتراض الثاني فيتمثل في مسارات نمو الاقتصاد العالمي، حيث أنه من المتوقع نمو محدود الوتيرة للاقتصاد العالمي نتيجة تأثر عدد من الدول بالتداعيات الاقتصادية الناتجة عن انتشار الفيروس وما تفضي إليه من تباطؤ أكثر من المتوقع لمستويات الطلب الخارجي والتجارة الدولية.

1 صندوق النقد العربي، تقرير آفاق الاقتصاد العربي، (أبريل 2020)، https://www.amf.org.ae/sites/default/files/aeo/2020/AEO_Apr_2020_v2.pdf 
بحيث يبدأ الاقتصاد العالمي بالتعافي بداية من عام 2021. ويتعلق الافتراض الثالث بأسعار

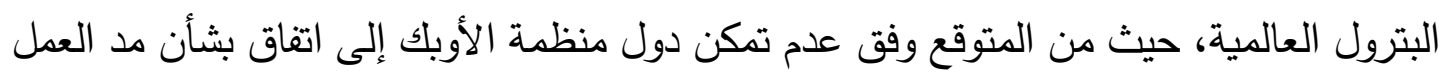
باتفاق "أوبك+"، إلى ما بعد مارس 2020، والتراجع المتوقع في مستويات نمو الطلب على لـ البترول بسبب تداعيات فيروس كورونا وما نتج عنه من انخفاض مستويات طلب بعض القطاعات الاقتصادية الأساسية على الوقود مثل قطاع الصناعة والطيران والتجارة في ظل اتجاه عدد كبير من الدول إلى فرض حظر واسع النطاق على انتقالات الأفراد أن تتسم الأسواق العالمية للبترول باستمرار تقوق مستويات المعروض البترولي خلال عام 2020. بناء عليه؛ من المتوقع أن ينعكس ذلك على مستويات الأسعار التي من المتوقع أن تتخفض إلى مستويات تتراوح بين دولار للبرميل 45-40 وفق سلة خامات أوبك خلال عام 2020، مع ارتفاع متوقع للأسعار لتدور حول 50 دولار للبرميل خلال عام 2021، مع التحسن التدريجي للنشاط الاقتصادي العام المقبل.

أما الافتراض الرابع الخاص بتوجهات السياسة النقدية؛ فمن المتوقع استمرار الموقف التيسيري للسياسة النقدية في البنوك المركزية العالمية الرئيسة ممثلة في كل من مجلس الاحتياطي الفيدرالي الأمريكي والبنك المركزي الأوروبي مع ما يستتبعه ذلك من تراجع أسعار الفائدة لمستويات صفرية

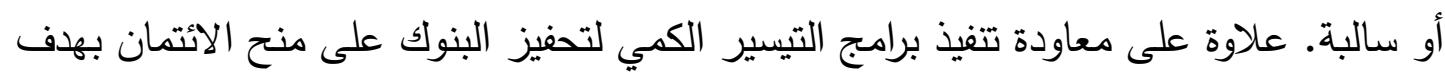
التخفيف من التبعات الاقتصادية لفيروس كورونا. هذه الاتجاهات التيسيرية للسياسة النقدية سوف تواكبها البنوك المركزية العربية المرتبط عملاتها بالدولار واليورو، وهو ما سيدعم اقتصاداتها في مواجهة هذه الظروف الاستثنائية.

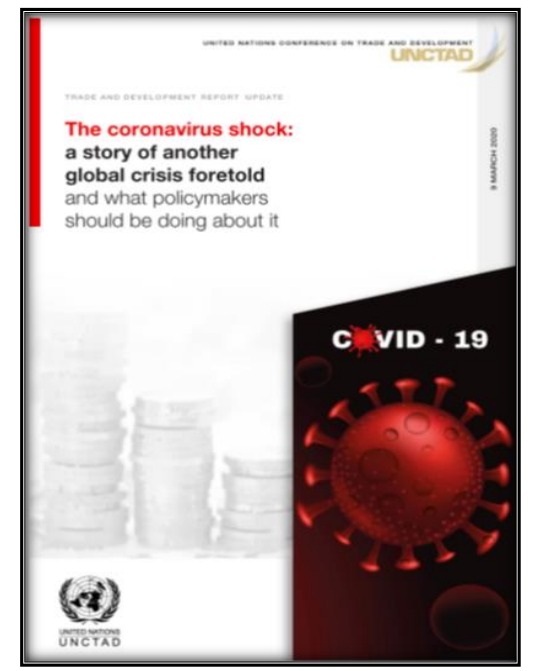

8. قصة أزمة عالمية أخرى تم التنبؤ بها وما يجب أن يفعله صانعو السياسة حيال ذلك

أخرى قد تصل في حدتها إلى الأزمة المالية العالمية التي حدثت عام 2008. 
وتعد الأونكتاد هيئة حكومية دولية دائمة أنثأتها الجمعية العامة للأمم المتحدة في عام 1964، وهي جزء من الأمانة العامة للأمم المتحدة.

وقد أكد التقرير على أنه من الضروري مواءمة الاستجابات لصدمة 19-Covid بطريقة تعيد

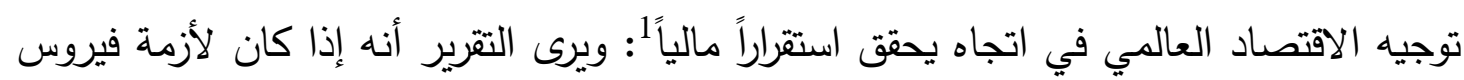
كورونا المستجد تأثيرات سلبية على إنفاق القطاع العائلي وقطاع الأعمال، فإنه يمكن للحكومات أن تتجنب ذلك الركود الناتج عن انخفاض الطلب وذللك عن طريق زيادة طلبها الخاص، وخاصة على قطاع التشييد والبناء وكذا الإنفاق على الخدمات الاجتماعية.

وأشاد التقرير بالسياسات التي تم تتفيذها في الدول المتضررة من تداعيات الأزمة حيث اشتملت على تعزيز الإنفاق الصحي الطارئ مؤقتًَا مع الرعاية المجانية للمتضررين من فيروس كورونا المستجد مما يعد استجابة واضحة، وينطبق الثيء نفسه على التحويلات النقدية الطارئة لأولئك الذين يعانون من فقدان مفاجئ للدخل، خاصة في الاقتصاد غير الرسمي.

وفي إطار الإعلان الترحيبي من صندوق النقد الدولي لتقديم 50 مليار دولار للتخفيف من آثار

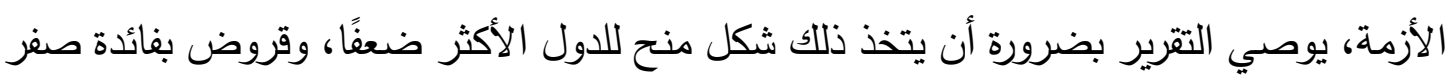
للدول الأخرى. كما يوصي التقرير بأنه يتعين على الحكومات الراغبة في القيام "بكل ما يلزم" لتحرئ لتحقيق الاستقرار في الاقتصاد أن تزيد من إنفاقها حتى يعود طلب القطاع الخاص والعمالة إلى لـ معدلات نمو طبيعية. في الأزمة الحالية، هناك أيضًا خطر إضافي يتمثل في أن الاستجابة المالية البطيئة يمكن أن تزيد من مخاطر العدوى العالية، وبالتالي يجب على الحكومات إعطاء إثارة واضحة بأن مخاوف الدين العام ثانوية بالنسبة إلى مخاوف الصحة العامة.

كما يؤكد التقرير على أنه في الوقت الراهن لا ينبغي الاعتقاد بأن المزيد من الإنفاق غير فعال خاصةً إذا واجهت الشركات اختناقات في سلاسل التوريد الخاصة بها. ويرى التقرير أن العائق الحقيقي الذي يواجهه الاقتصاد العالمي هو الإنفاق، خاصة للاستثمار في البنية التحتية المادية

\section{${ }^{1}$ UNCTAD, " The Coronavirus shock: a story of another global crisis foretold and what} policymakers should be doing about it" , March 2020, https://unctad.org/en/PublicationsLibrary/gds_tdr2019_update_coronavirus.pdf 
والاجتماعية وكذلك في البحث والابتكار الممولين من القطاع العام. علاوة على ذلك، فإن التقدم التقني ونمو الإنتاجية يتأثر سلباً بانخفاض الإنفاق في المجالات سالفة الذكر .

ويشير التقرير إلى أهمية معالجة التفاوتات الاقتصادية باعتبارها جزءًا أساسياً من استجابة السياسة

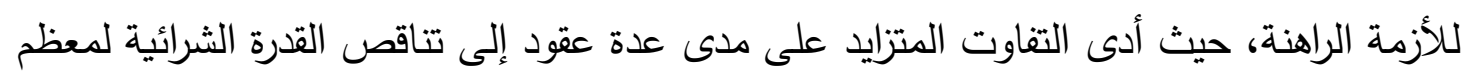
الأسر منذ فترة طويلة قبل تفشي جائحة فيروس كورونا المستجد، ويمكن تحقيق ذلك عن طريق العمل على دعم نمو العمالة، وتحفيز الإنفاق الحكومي لزيادة الأجور ، وتنظيم سوق العمل، وتأمين

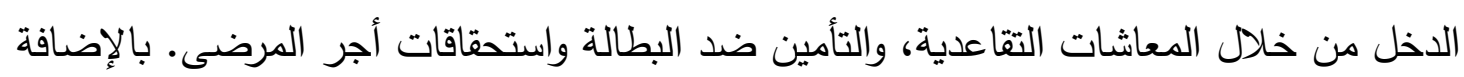
إلى ذلك يمكن معالجة التفاوتات الاقتصادية من خلال توفير الرعاية الصحية والتعليم.

وأوضح التقرير ضرورة توجيه اهتمامًا خاصًا بالأشخاص المصابين بالفيروس، حيث أن المجتمعات التي تتمتع بتغطية شاملة للتأمين الصحي هي في وضع أفضل لحماية نفسها من عواقب الوباء حيث لا يتحمل الناس أي تكلفة تتعلق بالإصابة بالفيروس، ويمكن علاج المصابين من قبل النظام الصحي الحكومي مع فقدان القليل من الدخل. كما أوصى التقرير بضرورة أن تخضع الممارسات الاحتكارية لشركات الأدوية العالمية الكبرى لفحص مستقل لتقييم أي عتبات محتملة قد تتتج لمعالجة حالة الطوارئ الناجمة عن أزمة كورونا.

وأوصى التقرير بأنه يجب على البنوك المركزية أن تعمل على مواجهة فيروس كورونا المستجد

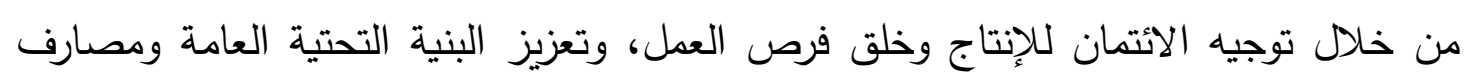
التمية، وتوفير خطوط ائتمان مصممة خصيصًا للشركات الصغيرة والمتوسطة المتعثرة مالياً. أما على الصعيد الدولي؛ فأثار التقرير إلى أنه ينبغي للمؤسسات المتعددة الأطراف مثل صندوق النقد الدولي أن تقدم آليات تحوط ملموسة منخفضة التكلفة لحكومات الدول النامية لإدارة مخاطر

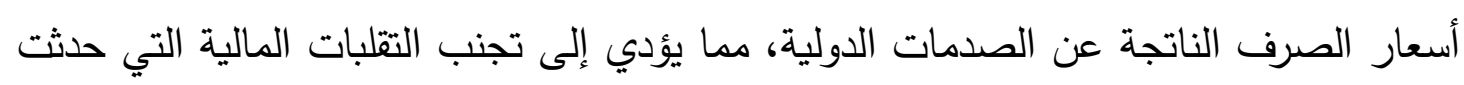

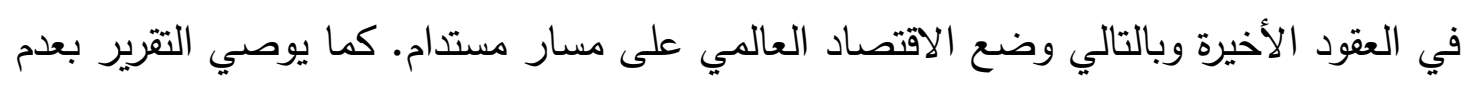

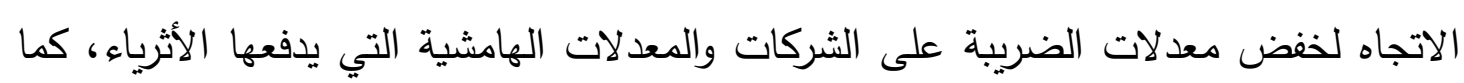
يجب العودة إلى الضرائب التصاعدية وتقليل الاعتماد على ضرائب القيمة المضافة التي تؤدي إلى تآكل الإنفاق الخاص. وأضاف التقرير أنه بالنسبة للعديد من الدول النامية التي لديها نسبة 
عالية من الديون، والتي غالباً ما تنفق بالفعل ما يصل إلى ثلث الإيرادات الحكومية على خدمة الديون، فيجب العمل على الوقف الفوري لسداد الديون عند إعلان حالة طوارئ صحية بهذا الحجم.

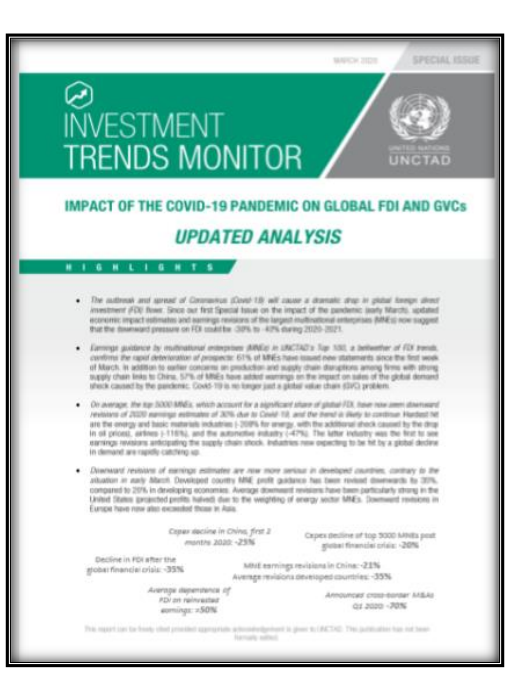

أثر وباء كورونا على الاستثمار الأجنبي المباشر وسلاسل

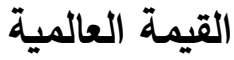

أصدرت الأونكتاد (مؤتمر الأمم المتحدة للتجارة والتتمية) في مارس 2020 تقريراً بعنوان "أثر وباء كورونا على الاستثمار الأحداد

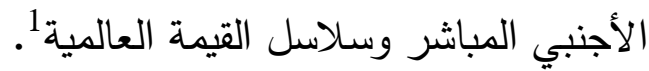

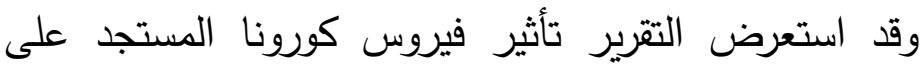

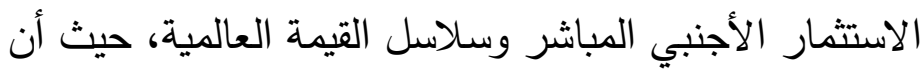

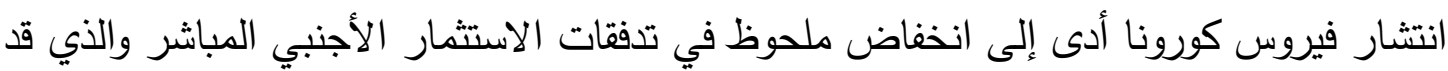
ينخفض إلى سالب 30\% أو سالب 40\% خلال 2020-2021.

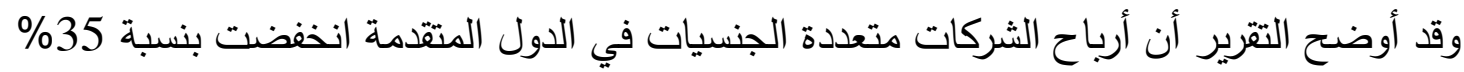

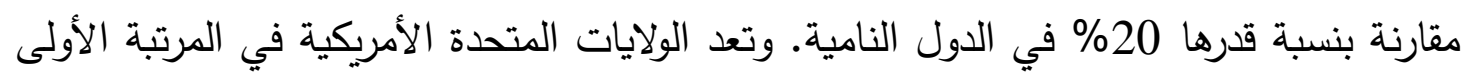
في خسائر الثركات متعددة الجنسيات يليها الدول الأوروبية ثم الدول الآسيوية.

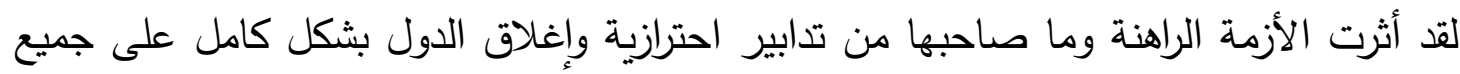

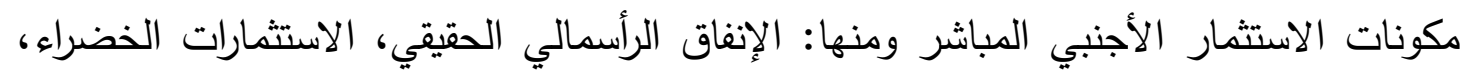

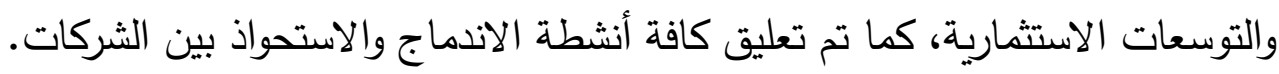
وقد أكد التقرير على أن الأثر السلبي للأزمة قد يصل إلى الأسوأ وذلك على عدة أصعدة:

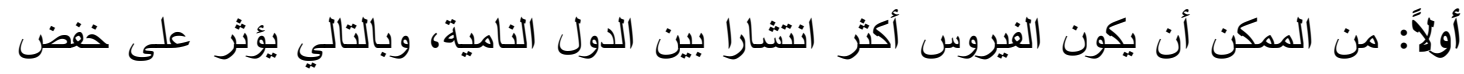
تدفقات الاستثمار الأجنبي المباشر في الدول النامية بنفس قوة التأثير على الدول المتقدمة أو بتأثير

1 UNCTAD, "Impact of the COVID-19 Pandemic on Global FDI and GVCs" https://openknowledge.worldbank.org/bitstream/handle/10986/33477/211565-ch01 .pdf, March 2020, https://unctad.org/en/PublicationsLibrary/diaeiainf2020d3_en.pdf 
ثانياً: أثر الأزمة قد يكون سريعاً بشكل ملحوظ، وذلك لأن الصدمات في جانب الطلب الكلي وثيقة

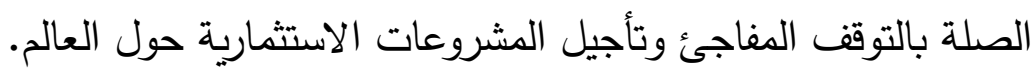

ثالثاً: بالرغم من أن سبب هذه الجائحة لا يعد مثل سبب الأزمة المالية العالمية التي حدثت عام 2008، إلا أنها أثرت بشدة على مناخ الأعمال بحيث عجزت لالئ الثركات عن سداد التزاماتها المالية، مما كان له تداعيات سلبية أخرى على تدفقات الاستثمار العالمي.

INTERNATIONAL MONETARY FUND

9.تقرير آفاق الاقتصاد العالمي

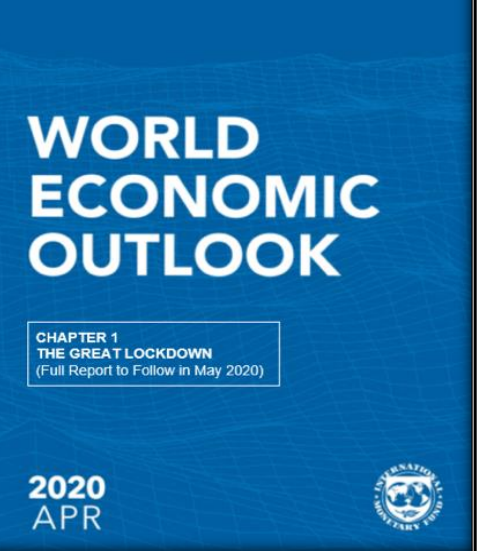

أصدر صندوق النقد الدولي في أبريل 2020 الفصل الأول من

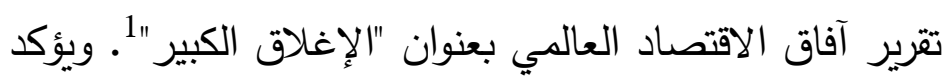

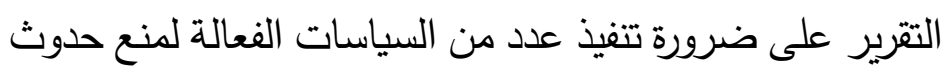

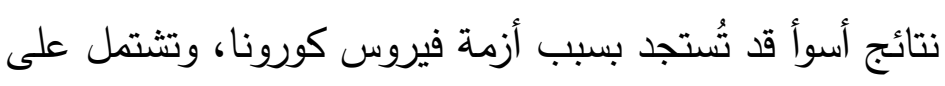
أهمية تتفيذ التدابير اللازمة للحد من العدوى وحماية الأرواح.

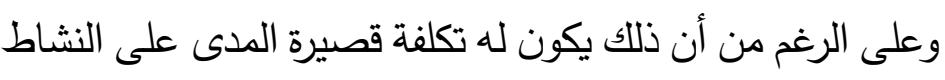
الاقتصادي، لكن يجب أن ينظر إليها أيضًا على أنها استثمار

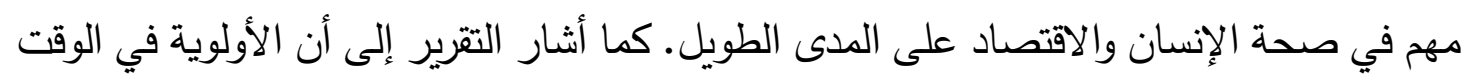

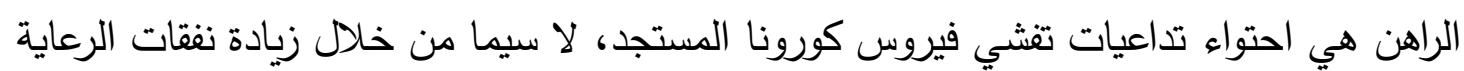

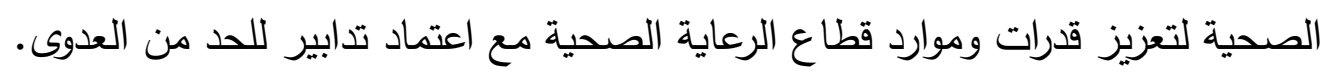

ويوصي التقرير الدول بضرورة اتباع عدد من السياسات الاقتصادية التي تخفف من حدة الأثر

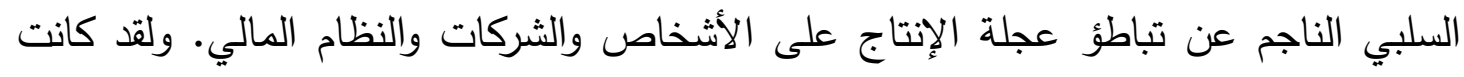
الاستجابة المالية في الدول المتأثرة سريعة وكبيرة في العديد من الاقتصادات على الإندات المتقدمة مثل أستراليا

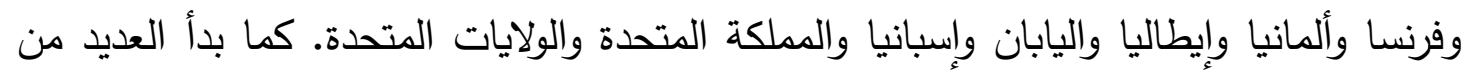
الأسواق الناشئة والاقتصادات النامية مثل الصين وإندونيسيا وجنوب إفريقيا في تقديم أو الإعلان عن دعم مالي كبير للقطاعات والعمال المتضررين بشدة.

وأشار التقرير إلى أنه يجب رفع مستوى الإجراءات المالية المتخذة إذا استمر التوقف عن النشاط

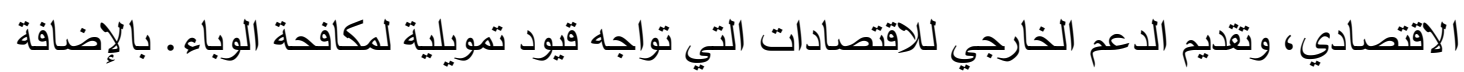

1 IMF, "World Economic Outlook", April 2020,

https://www.imf.org/ /media/Files/Publications/WEO/2020/April/English/text.ashx?la=en 


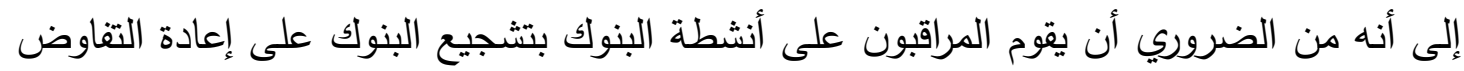

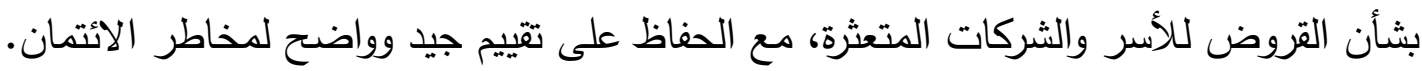

وأكد التقرير على أهمية تعزيز التعاون متعدد الأطراف بين الدول والمؤسسات التمويلية الدولية

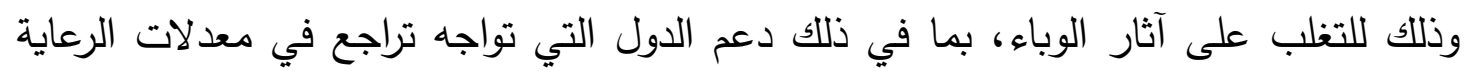
الصحية بالإضافة إلى القيود التمويلية، بالإضافة إلى التعاون في التوصل إلى دلى لـألى لقاح وأدوية لمواجهة

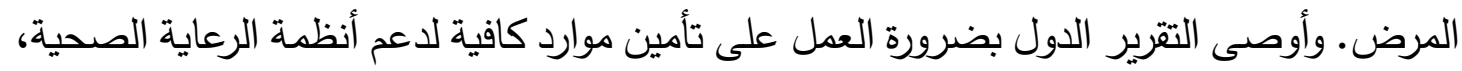

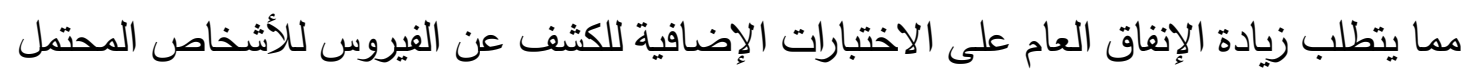
إصابتها، وإعادة توظيف الأطباء المتقاعدين، وشراء معدات الوقاية الثخصية وأجهزة التهوية،

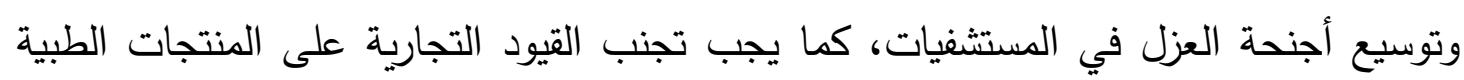
والصحية للمساعدة على وصولها للدول الأكثر تضرراً والأكثر احتياجاً.

وأثار التقرير إلى أنه يجب توسيع برامج الدعم الحالية وإدخال برامج جديدة حيثما كان ذلك مدكناً

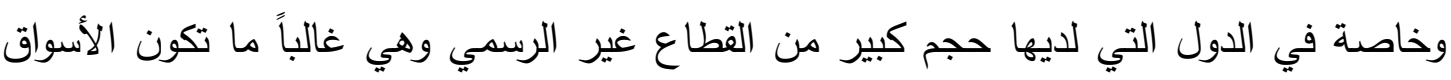

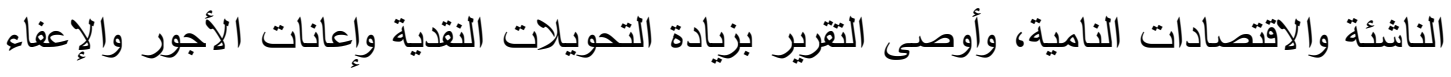
الضريبي ومد آجال استحقاق الديون. أما على مستوى السياسات النقدية؛ فق أثار التقرير إلى أنه النه يجب على البنوك المركزية أن توفر سيولة كافية للبنوك وشركات التمويل غير المصرفية، لا سيما تلك التي تمنح قروضاً للشركات الصغيرة والمتوسطة، والتي قد تكون أقلى استعدادًا في مواجهة تداعيات أزمة فيروس كورونا المستجد.

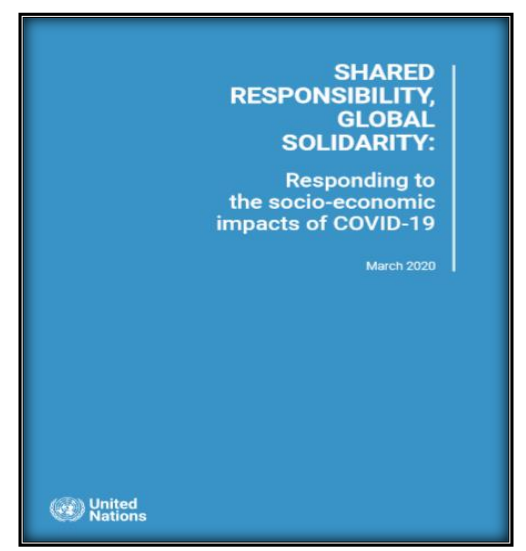

10. المسؤولية المشتركة والتضامن العالمي: الاستجابة للآثار الاجتماعية والاقتصادية لفيروس كورونا المستجد النداند

أصدرت الأمم المتحدة تقريراً في مارس 2020 يناقش المسؤولية المشتركة والتضامن العالمي: الاستجابة للآثار الاجتماعية

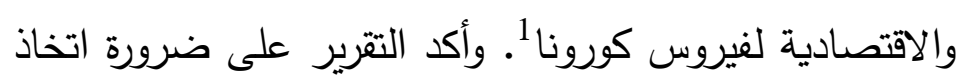
إجراءات حاسمة وعاجلة ومتسقة من قبل جميع قادة الدول

\footnotetext{
1 United Nations, " Shared Responsibility, Global Solidarity: Responding to the socio-
} economic impacts of COVID-19", March 2020،

https://unsdg.un.org/sites/default/files/2020-03/SG-Report-Socio-Economic-Impact-ofCovid19.pdf 
والشركات ومؤسسات التمويل ومنظمات المجتمع المدني لمنع انتقال الفيروس في أسرع وقت ممكن

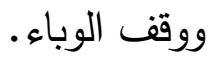

ولقد أبرز التقرير مجموعة من التوصيات التي تتمثل في أنه يجب على جميع الدول العمل على تتفيذ استراتيجيات صحية شاملة وسريعة تهدف إلى تقليل عمليات انتقال العدوي وتحجيم انتشاره

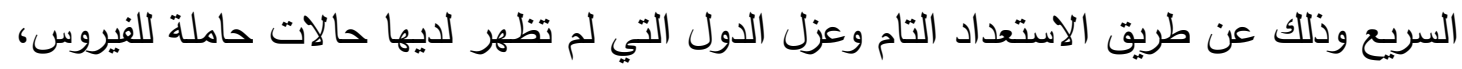

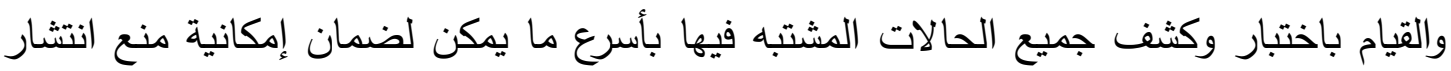

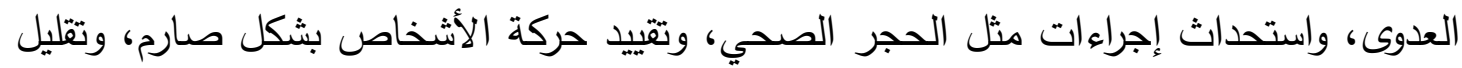
الاتصال المباشر بين الأشخاص بشكل عام عن طريق إغلاق العمل والمدارس، والتباعد الاجتماعي وتتثيف المجمعات حول الحد من الانتشار من خلال غسل اليدين، وتوفير رعاية سريرية آمنة وفعالة لعزل جميع حالات فيروس كورونا المستجد بشكل فعال، وحماية العاملين في مجال الرعاية الصحية والحفاظ على الإمدادات الطبية الأساسية من خلال الإدارة الفعالة لسلسلة التوريد، بالإضافة إلى تبادل المعرفة وتطوير الأدوية واللقاحات الجديدة، ومراعاة إدماج الفئات المحرومة من السكان الإدان

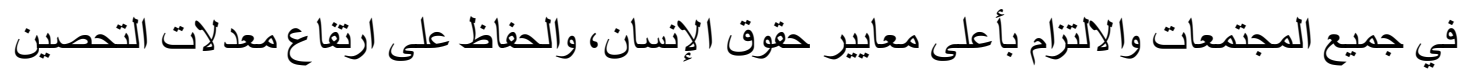
للوقاية من الحصبة وشلل الأطفال والكوليرا.

وقد أوصى التقرير أيضاً بأهمية تقديم الدعم العاجل للدول النامية ذات النظم الصحية الضعيفة،

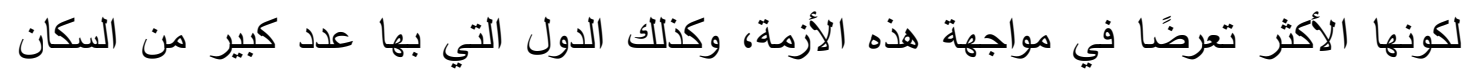

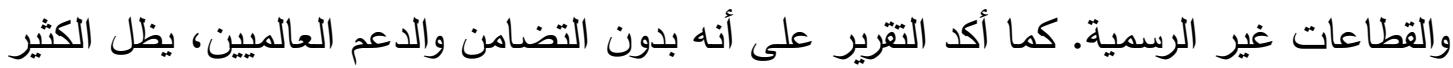

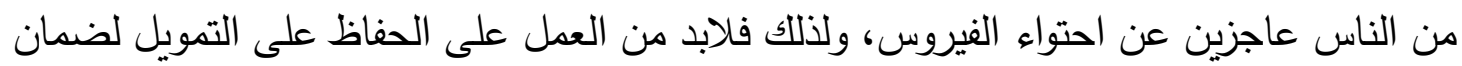

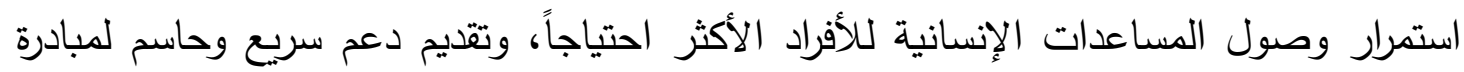

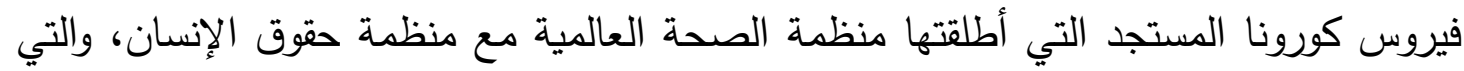
ستساعد 51 أو أكثر من الدول الأكثر ضعفاً والمتضررة من النزاع في الثرق الأوسط وآسيا وأفريقيا

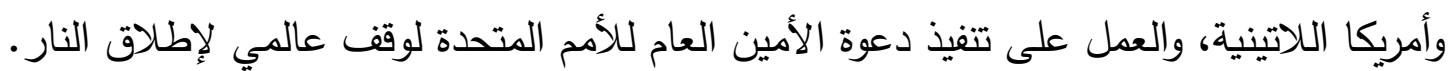

ويشير التقرير في توصياته إلى ضرورة السماح بالوصول المجاني والفوري لنتائج الأبحاث العلمية

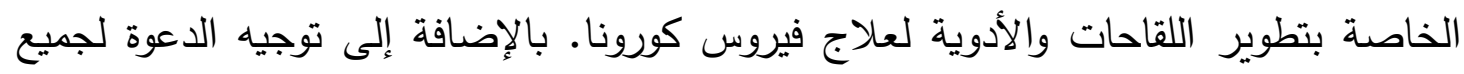
الثركات وممثلي القطاع الخاص للالتزام بإشادات الصحة والسلامة وتوفير التدابير الاحترازية لإصلية للعمال، بما في ذلك من خلال ضمان سلامة العمال والتباعد الاجتماعي وتأمين الأجور للعاملين من المنزل، وتقديم الدعم المالي والتقني للحكومات من خلال المساهمة في صندوق استجابة الدانية

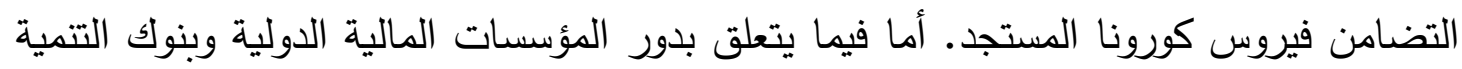


الإقليمية في معالجة أثر الأزمة فيوصي التقرير بضرورة العمل على تمويل الدول الأكثر تضررا واحتياجاً.

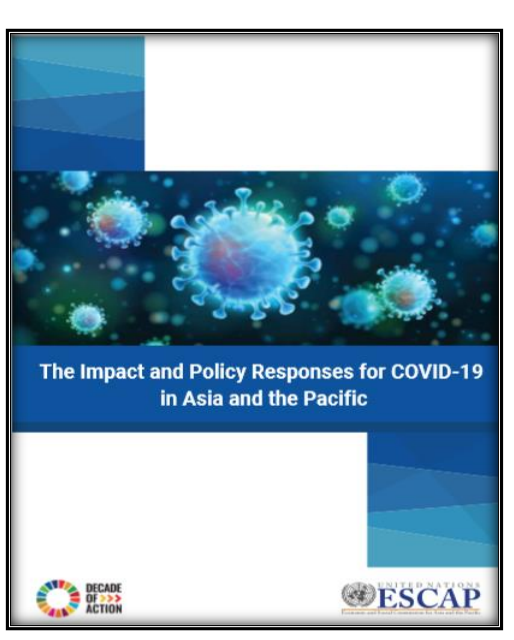
11 11. أثر فيروس كورونا واستجابات السياسات تجاهه في

أصدرت اللجنة الاقتصادية والاجتماعية لآسيا والدحيط الهادئ

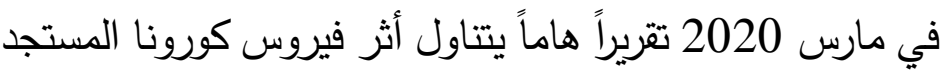
واستجابة السياسات لتلك الأزمة في آسيا والمحيط الهادئ فئران. وتعمل اللجنة الاقتصادية والاجتماعية لآسيا والمحيط الهادئ

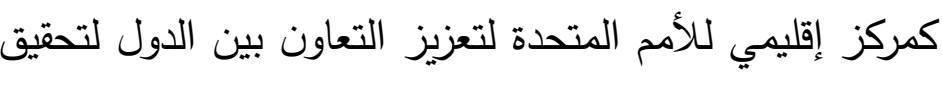
التنمية الثاملة والمستدامة.

ويقدم هذا التقرير عرضاً للآثار والتداعيات الرئيسية لفيروس كورونا المستجد في منطقة آسيا

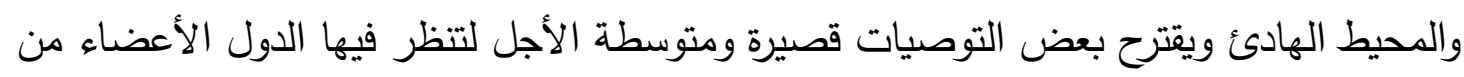

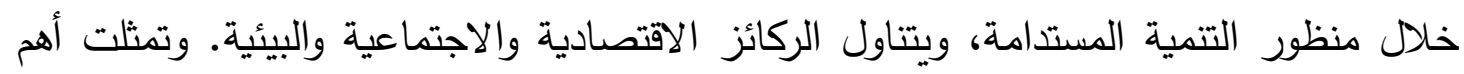
التوصيات التي قدمها التقرير في أنه ينبغي توجيه السياسة النقدية لاعم استقرار التمويل البنكي. ويمكن القيام بذلك عن طريق توفير سيولة كافية للجهاز المصرفي. ويتطلب تتفيذ هذا الإجراء تخفيض أسعار الفائدة من قبل البنوك المركزية، بالإضافة إلى إزالة التعريفة الجمركية وغير لئي

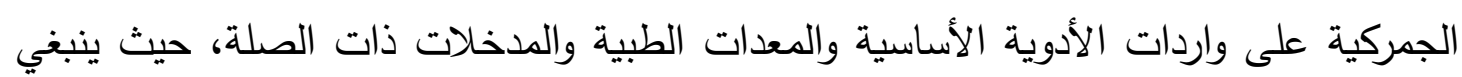

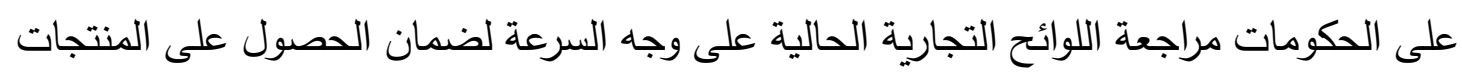

$$
\text { الطبية في الوقت المناسب وبأسعار معقولة. }
$$

كما أوصى التقرير بضرورة الاستعداد المسبق للطوارئ لتقليل الآثار الاقتصادية المحتملة لأي أزمة

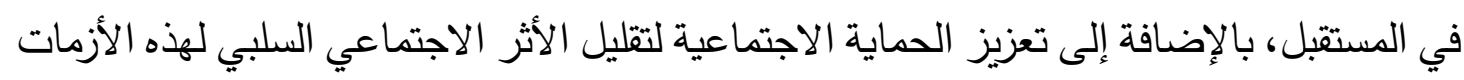

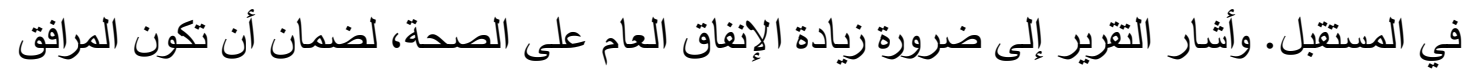

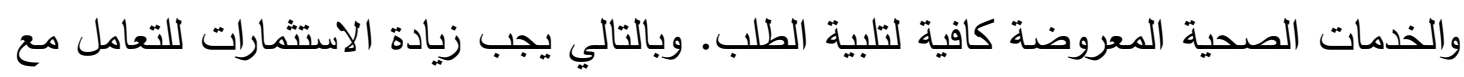

${ }^{1}$ United Nations, ESCAP, "The Impact and Policy Responses for COVID-19 in Asia and the Pacific", March 2020, https://www.unescap.org/sites/default/files/COVID\%20_Report_ESCAP.pdf 
مثل هذه الأزمات في المستقبل، الأمر الذي يتطلب وجود حيز مالي ضخم وبالتأكيد سوف يؤدي ذللك إلى زيادة في عجز الموازنة والدين العام.

أما بالنسبة للدول الفقيرة، فأوصى التقرير بضرورة التتسيق الإقليمي لتخفيف الديون أو تأجيل سداد

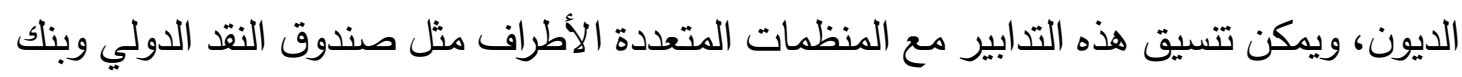

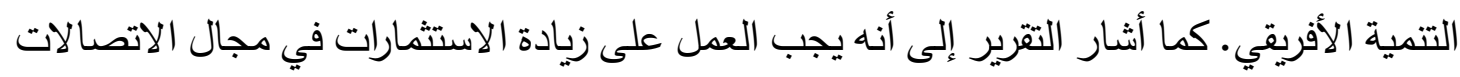

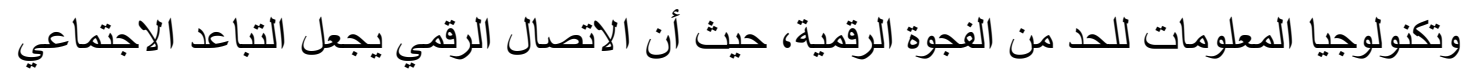

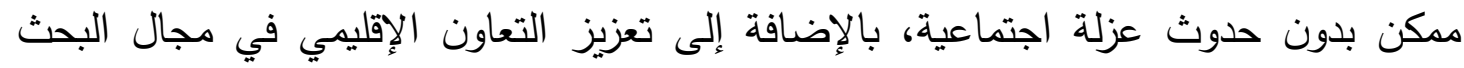

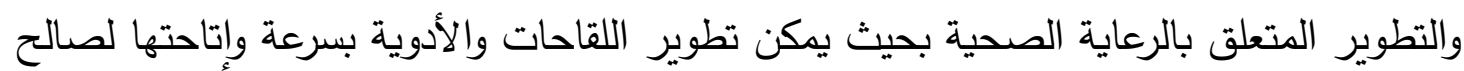

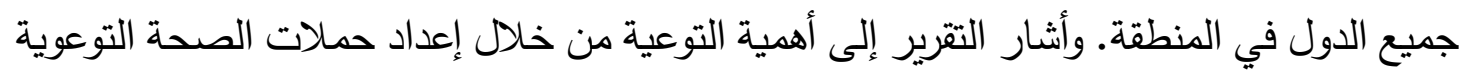

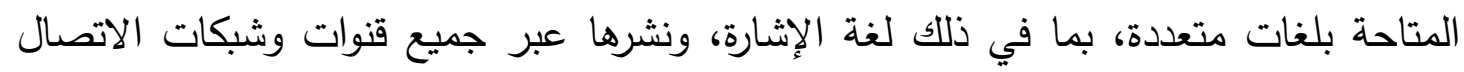

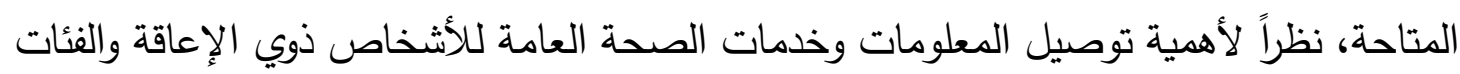

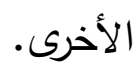

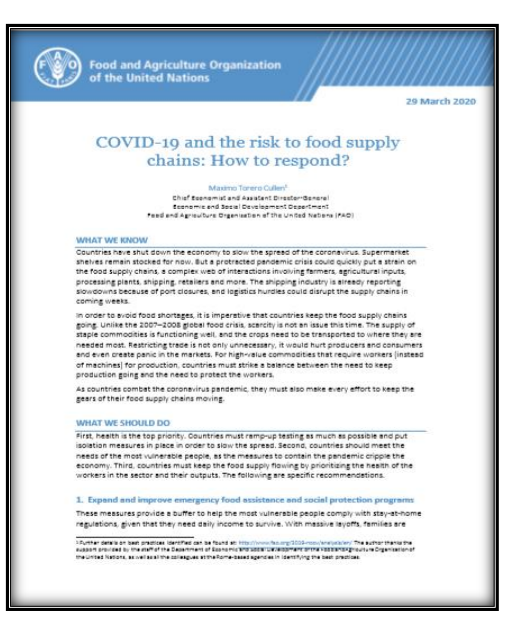

12. فيروس كورونا المستجد والمخاطر على سلاسل الإمداد الغذائي: كيفية الاستجابة

أصدرت منظمة الأغذية والزراعة للأمم المتحدة (الفاو) في

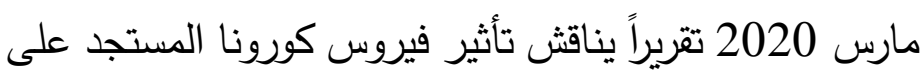

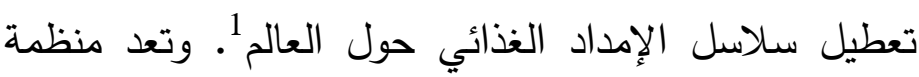

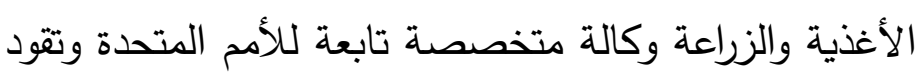
الجهود الدولية للقضاء على الجوع.

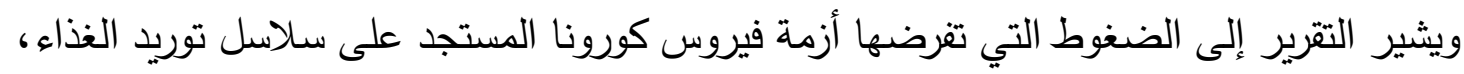

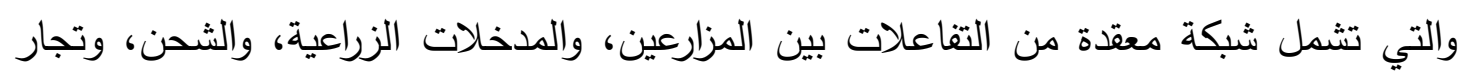

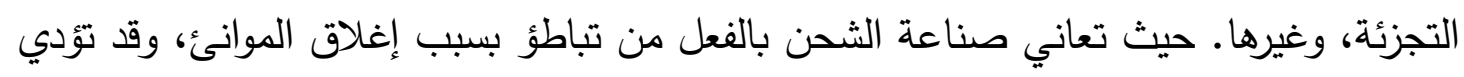

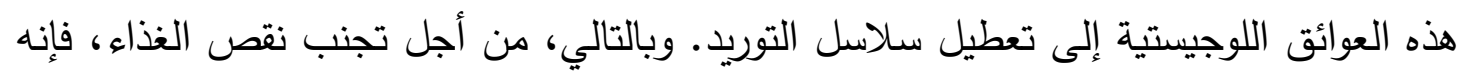
من الضروري أن تحافظ الدول على استمرار سلاسل توريد الغذاء.

${ }^{1}$ FAO, " COVID-19 and the risk to food supply chains: How to respond?", March 2020, http://www.fao.org/3/ca8388en/CA8388EN.pdf 
فعلى عكس أزمة الغذاء العالمية 2007-2008، فالمشكلة لا تتعلق بندرة الغذاء، إنما بتقييد

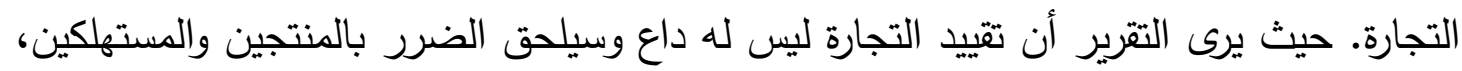

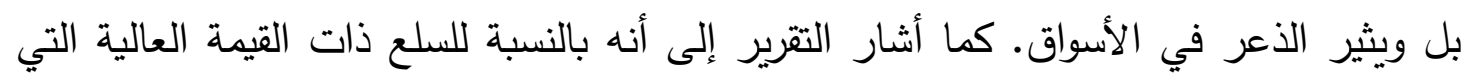

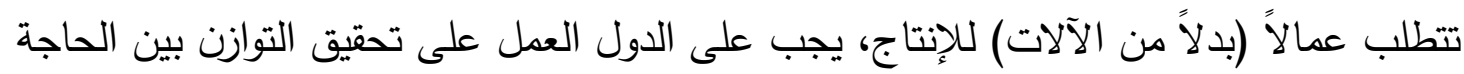
إلى استمرار الإنتاج والحاجة إلى حماية العمال.

وقدم التقرير مجموعة من التوصيات أهمها ضرورة تبذل الدول قصارى جهذها للحفاظ على الوتيرة الطبيعية لسلاسل توريد الغذاء منها وإلى غيرها، والعمل على توسيع المساعدة الغذائية الطارئة

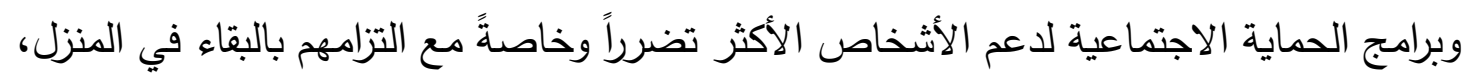

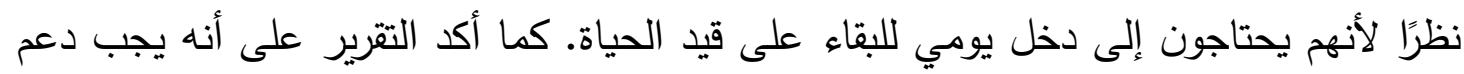

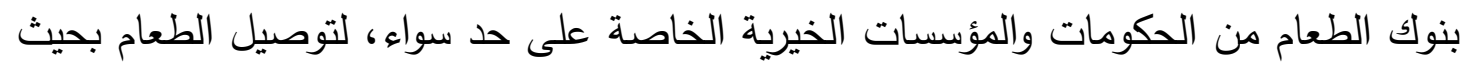
تبقى العائلات في المنزل، وخاصًة المسنين أو المصابين بأمراض مزمنة.

ويشير التقرير إلى أنه من الأهمية بمكان تعزيز دور شبكات الحماية الاجتماعية في ظل التداعيات السلبية لجائحة كورونا، كما حدث في عدد من دول العالم، بالإضافة إلى تقديم الدعم لصغنار

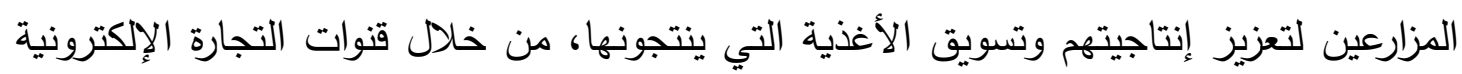

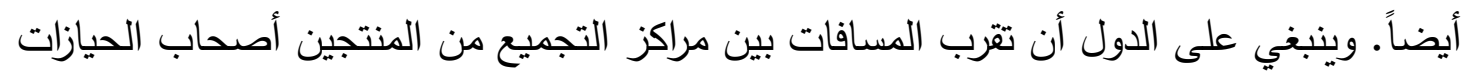
الصغيرة لتقليل الحاجة إلى التتقل، كما يجب أن يكون لمراكز التجميع سعة عالية.

ويوصي التقرير بضرورة الإسراع في تتمية التجارة الإكترونية لصغار المزارعين، وحصول صغار

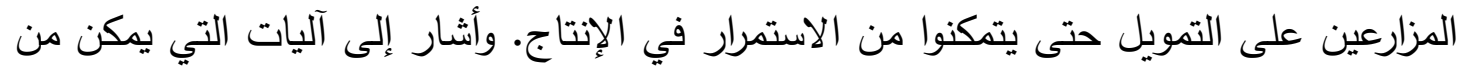

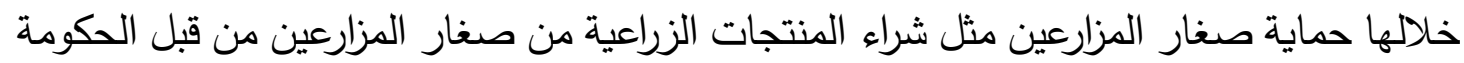
لتعزيز احتياطيات الطوارئ الاستراتيجية وخاصة للسلع غير القابلة للتلف لتعزيز الإمدادات الغذائية.

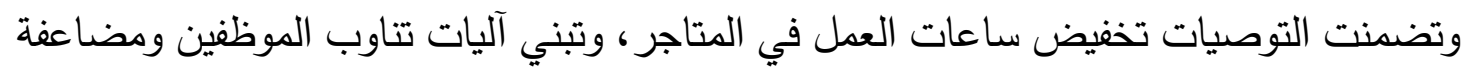

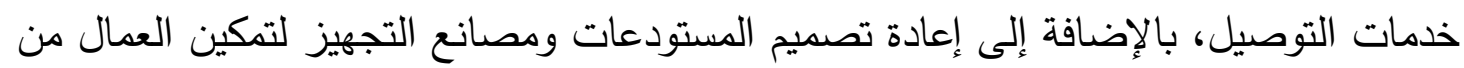

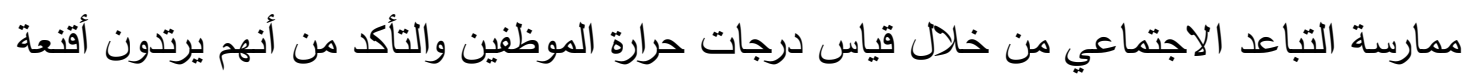

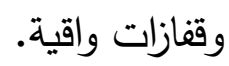

وأكد التقرير على ضرورة دعم الدول الفقيرة في الحصول على تمويل دولي لدعم صغار المزارعين

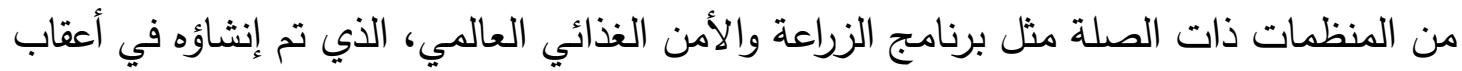


أزمة الغذاء 2007-2008 لهذا الغرض، فضلاً عن ضرورة التخفيض المؤقت لضريبة القيمة المضافة والضرائب الأخرى للمساعدة في استقرار أسواق الغذاء العالمية.

INTERNATIONAL MONETARY FUND

13. تقرير الاستقرار المالي العالمي

أصدر صندوق النقد الدولي في أبريل 2020 تقريراً بشأن

GLOBAL

FINANCIAL

STABILITY

REPORT

CHAPTER 1
Global Financial Stability Overview:

\begin{tabular}{|l|} 
Global Financial Stability Overview: \\
Markets in the Time of Covid-19
\end{tabular}

(Full Report to Follow in May 2020)

2020

APR

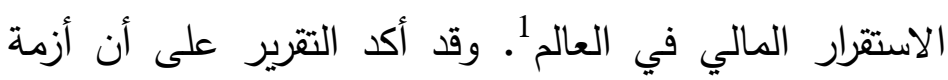
فيروس كورونا المستجد تمثل تهديدًا خطيرًا للغاية لاستقرار

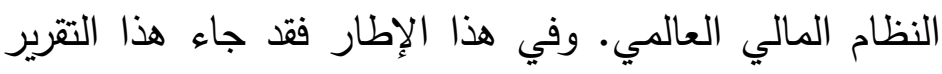

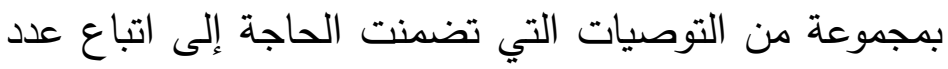

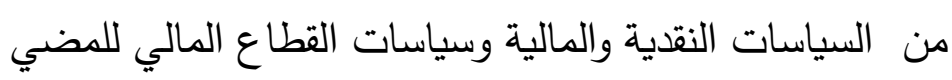

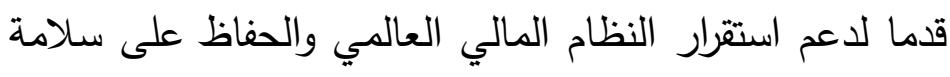
المؤسسات المالية، خاصة إذا ظل النشاط الاقتصادي متوقفاً

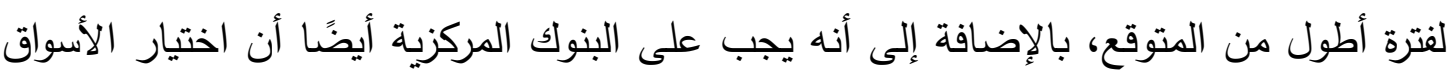

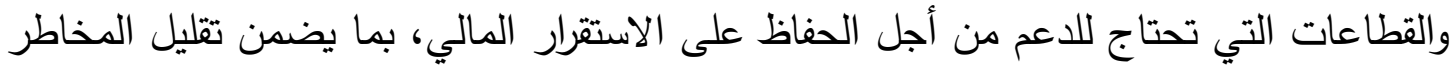

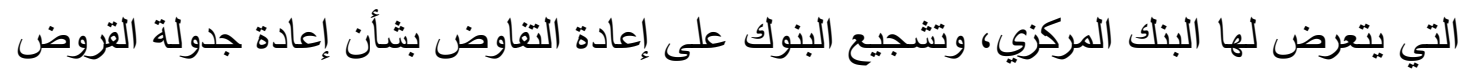

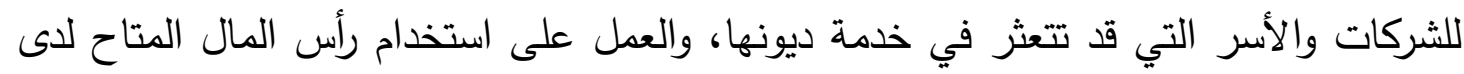

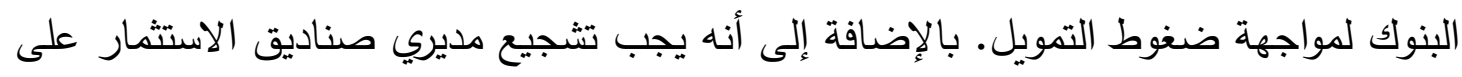

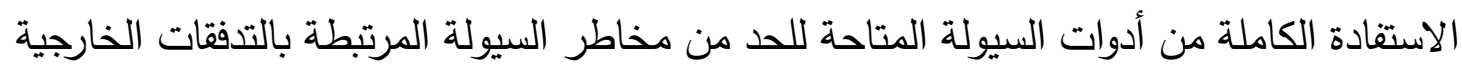
الكبيرة.

ويوصي التقرير بضرورة تعزيز التعاون الدولي لتجنب التحكم في الأسعار وتخفيف القيود التجارية على الإمدادات الطبية الأساسية، ووضع خطط طوارئ للتعامل مع الديون السيادية وذلك من خلال

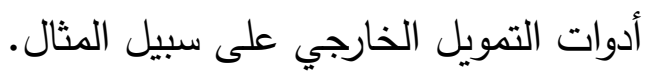

تواجه العديد من اقتصادات الأسواق الناشئة بالفعل ظروفًا متقلبة في السوق ويجب إدارة مثل هذه

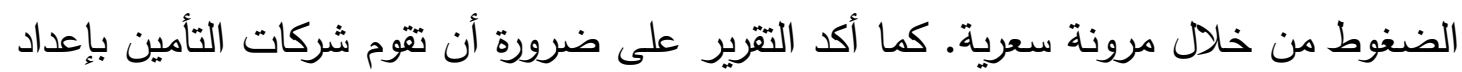
خطط موثوقة لضمان قدرتهم على الحفاظ على أوضاع الملاءة المالية أو استعادتها مع الاستمرار في توفير التغطية التأمينية اللازمة لحاملي بوالص التأمين.

${ }^{1}$ IMF, " Global Financial Stability Report", April 2020,

https://www.imf.org/ /media/Files/Publications/GFSR/2020/April/English/text.ashx?la=en 


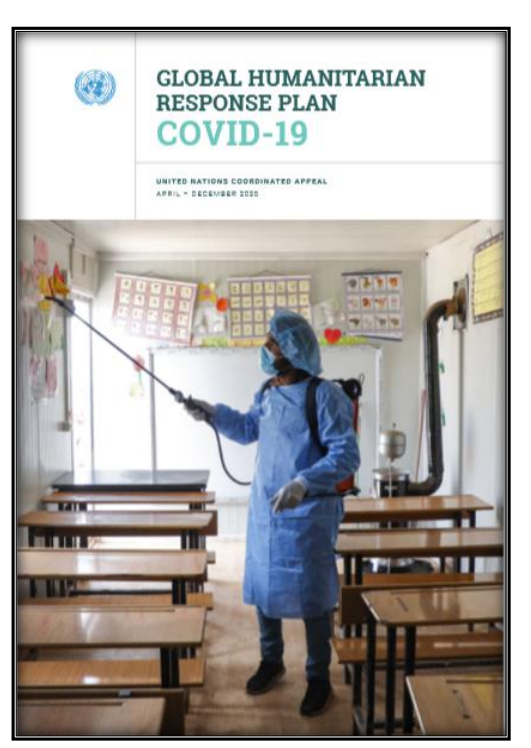

14. خطة الاستجابة الإنسانية العالمية لفيروس كورونا

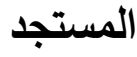

أصدر مكتب الأمم المتحدة لتنسيق الشئون الإنسانية في أبريل

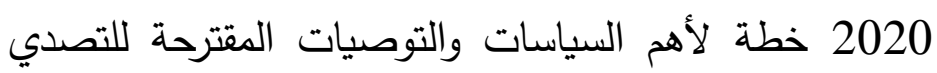
لتبعات أزمة فيروس كورونا المستجد ${ }^{1}$

ويعد مكتب تتسيق الثؤون الإنسانية جزءاً من الأمانة العامة

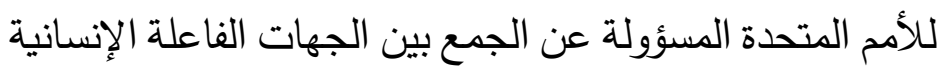
لضمان الاستجابة السريعة لحالات الطوارئ.

وتهدف خطة الاستجابة الإنسانية العالمية إلى تمكين الدول من مكافحة فيروس كورونا المستجد

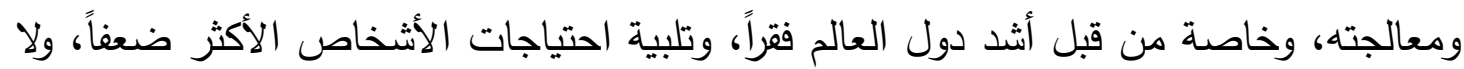
سيما النساء والأطفال والمسنين والمعوقين.

واعتمدت الخطة على مجموعة من التوصيات التي تتمثل في ضرورة الاستعداد لزيادة الاستجابة الإنسانية للأشخاص الأكثر تأثراً واستمرارية المساعدة في قطاعات متعددة، ولا سيما الصحة والمياه

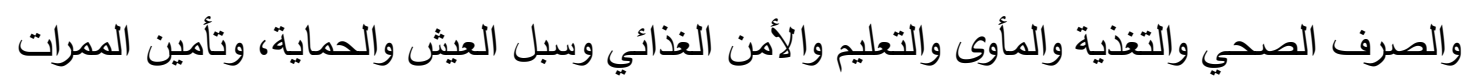

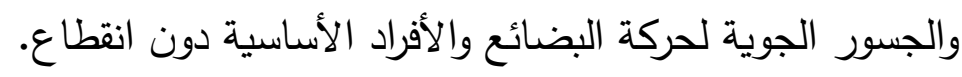

كما تضمنت التوصيات الخاصة بالخطة تعزيز منظومة الصرف الصحي والنظافة والخدمات

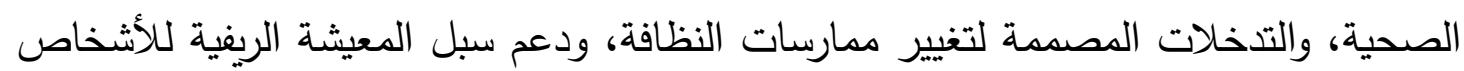
الذين يعانون من فقدان الأمن الغذائي وسوء التغذية وخاصة في الدول التي تعاني من أزمات غذائية مع استمرار تشغيل الأسواق المحلية وتعزيز سلاسل القيمة في تلك الدول.

وأوصى التقرير بضرورة تعزيز خدمات الحماية والخدمات الاجتماعية والنفسية والقانونية والعدالة لجميع أفراد المجتمع، بما في ذلك اللاجئين والمهاجرين، وتوفير المأوى وتحسين البنية التحتية

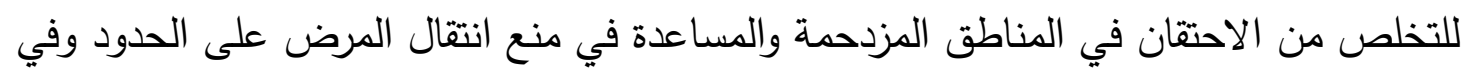

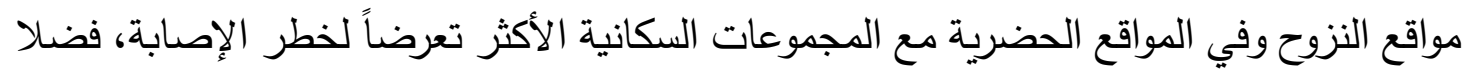

${ }^{1}$ UNOCHA, " Global Humanitarian Response Plan: COVID -19",

https://www.unocha.org/sites/unocha/files/Global-Humanitarian-Response-Plan-COVID-

19.pdf 
عن العمل على توسيع نطاق أنظمة المساعدة الاجتماعية وبرامج التحويلات النقدية (بما في ذلك التكال التصات

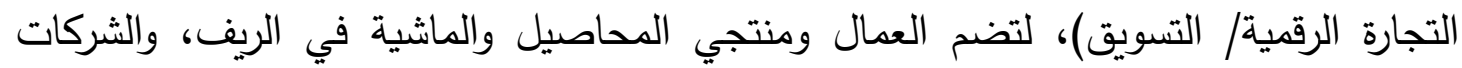

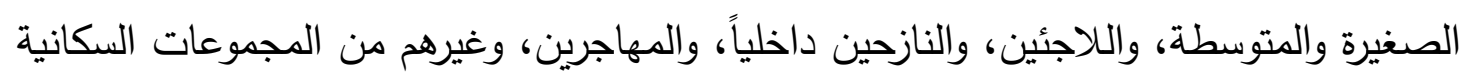

$$
\text { التي تضررت كثيرا بسبب جائحة فيروس كورونا. }
$$

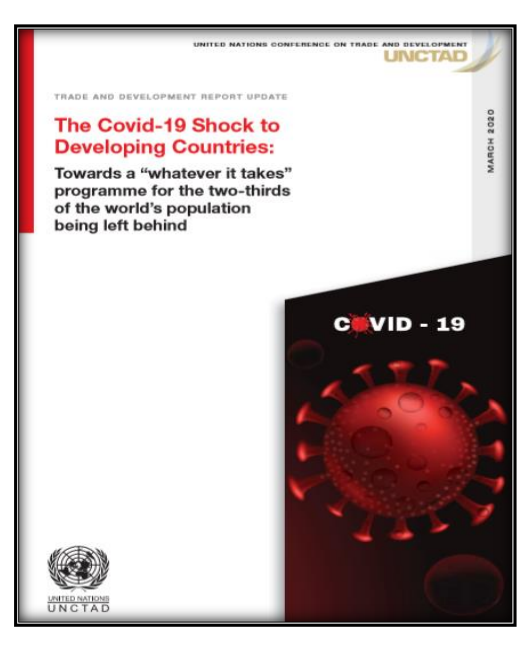

15. صدمة فيروس كورونا المستجد للدول النامية: نحو برنامج "مهما كلف الأمر" لثلثي سكان العالم المتخلفين عن الركب

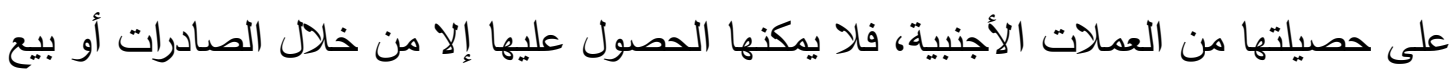

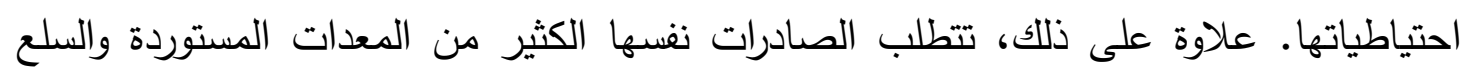
الوسيطة والتسهيلات المالية لذلك. وقد تسبب الاضطراب المالي الناجم عن أزمة كورونا بالفعل فلئل

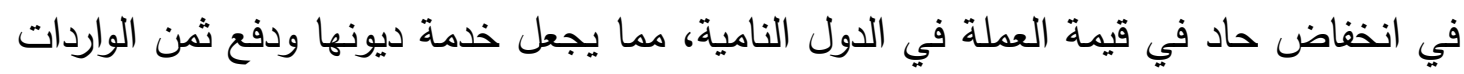
اللازمة لأنشطتها الصناعية أكثر إرهاقًا.

ويتوقع التقرير ثلاثة تحديات أساسية في ظل انتشار فيروس كورونا المستجد تتمثل في تزايد

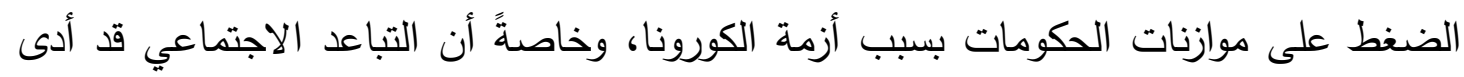

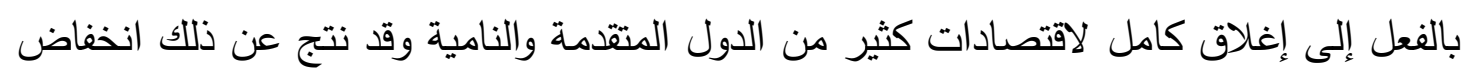

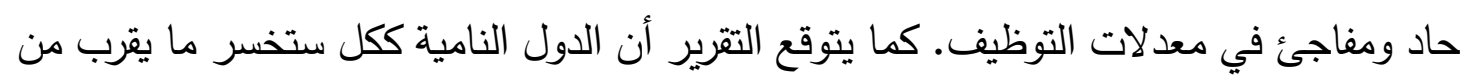

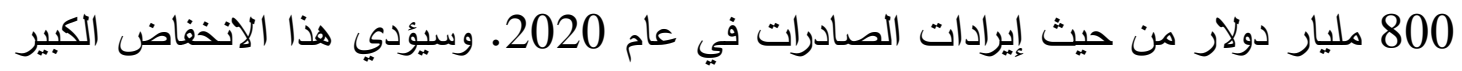
في أرباحها من العملات الأجنبية إلى زيادة التحديات التي يفرضات التها بات فالفعل انخفاض قيمة العملة

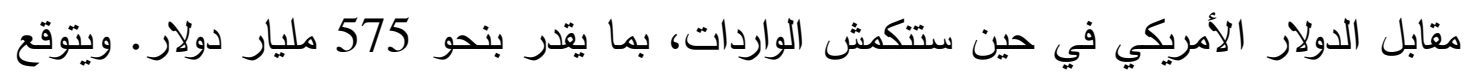

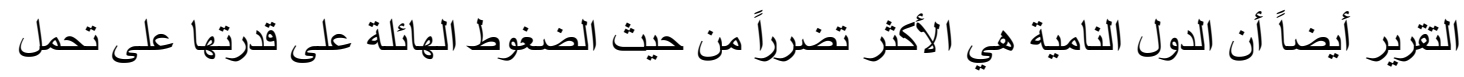
1 UNCTAD, " The COVID- 19 shock to Developing Countries: Towards a "whatever it takes" program for the two thirds of the world's population being left behind", March 2020, https://unctad.org/en/PublicationsLibrary/gds_tdr2019_covid2_en.pdf 
ديونها، وتتمثل تلك الضغوط في عدم إمكانية الوصول في المستقبل إلى مصادر لتمويل التزامات الديون الخارجية المستحقة وخاصةً مع تزايد تكلفة الدين بسبب ارتفاع قيمة العملة الأجنبية. وبالتالي؛ يؤكد التقرير ضرورة أن يقوم المجتمع الدولي بتنسيق حزم الإنقاذ الاقتصادي المناسبة

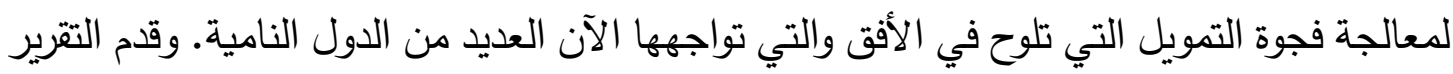

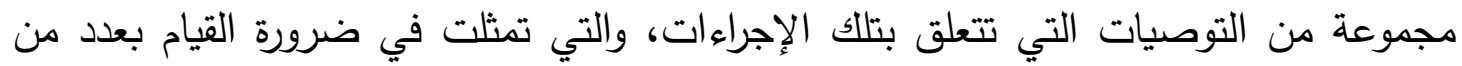

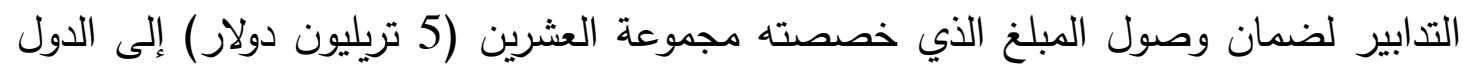

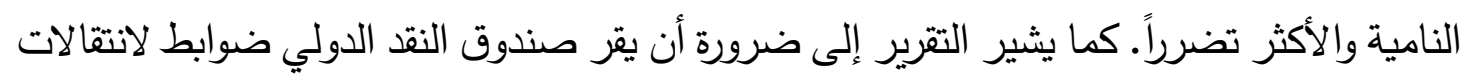

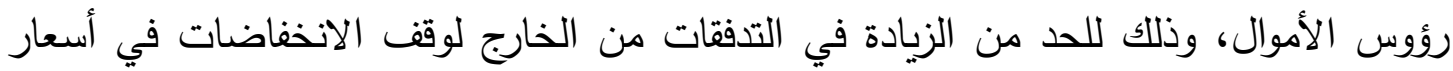

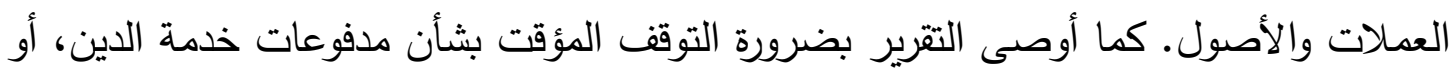

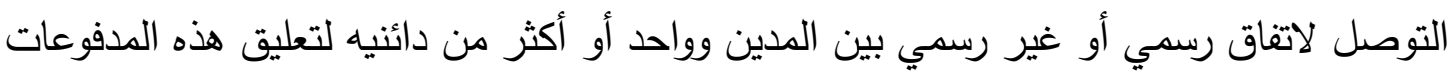

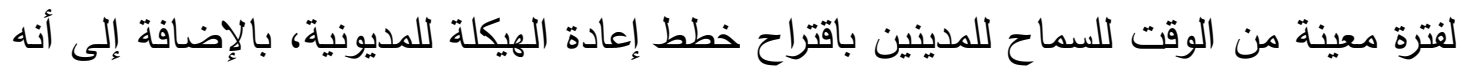
يجب على الدول المانحة تعزيز المساعدات الإنمائية الرسمية حيث تظل المساعدة الإنمائية الرسمية مصدراً حيوياً للتمويل الخارجي لأفقر الدول النامية.

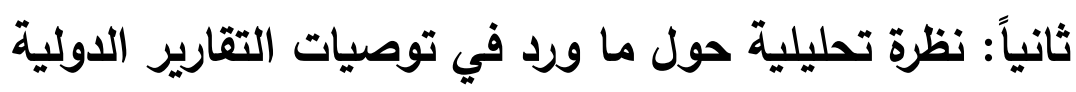

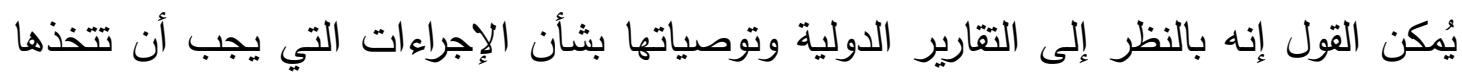

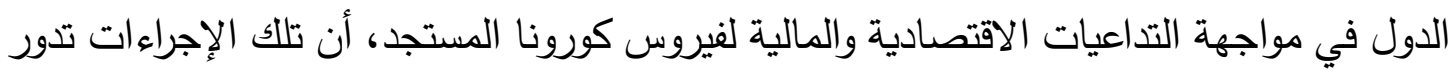

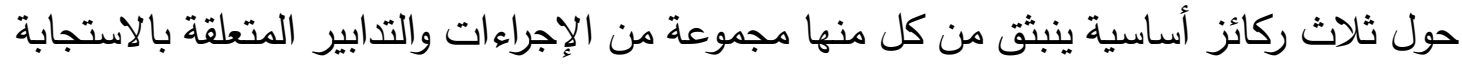
للأزمة. وتتمثل الركيزة الأولى في السياسة المالية التي من خلالها يتم تقديم الدعم النقدي للأفراد والأسر والقطاعات الأكثر تضرراً عن طريق شبكات الحماية الاجتماعية وغيرها من الأدوات

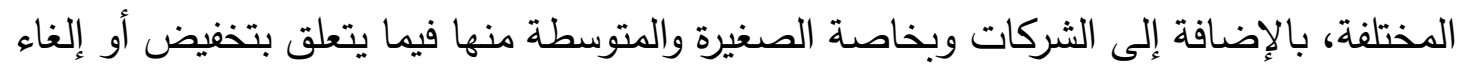

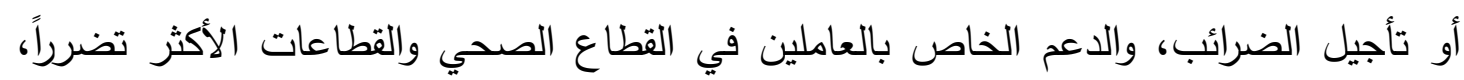

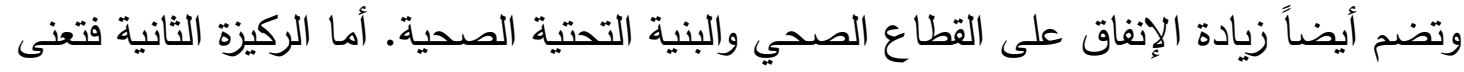

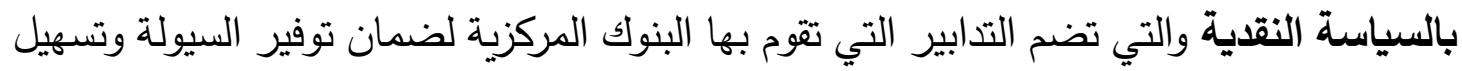
الإجراءات وتخفيف القيود المتعلقة بسعر الفائدة، وتوجيه الإرشادات إلى المؤسسات المالية المصرفية وغير المصرفية لتقديم الدعم للأفراد والثركات، وخاصة الصغيرة والمتوسطة من خلال

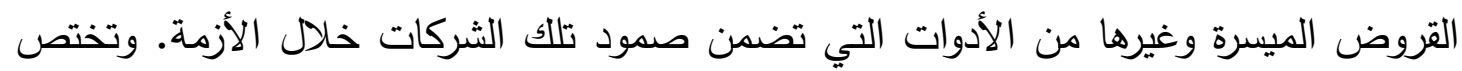
الركيزة الثالثة بالتعاون الدولي لمواجهة الأزمة من خلال العمل على رفع العات العبء عن الدون الدول النامية عن طريق تخفيف عبء الديون وإعادة جدولة سدادها، وتعزيز المساعدات المقدمة إلى الدول

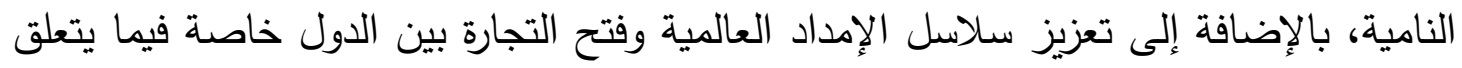


بتصدير واستيراد المنتجات الطبية، فضلاً عن تقديم الدعم من المؤسسات الدولية مثل صندوق النقد الدولي والبنك الدولي وغيرهما.

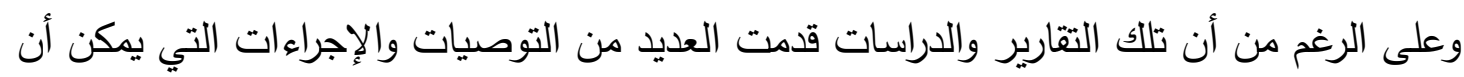

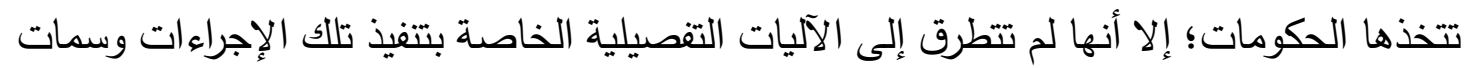

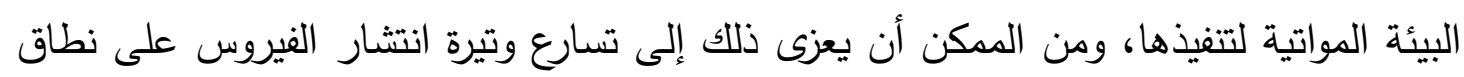

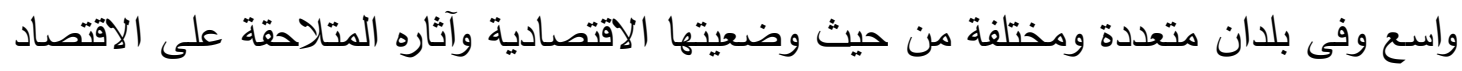
العالمي نتيجة للغلق الكامل للعديد من الأنشطة الاقتصادية، مما أدى إلى أن تتظر المؤسسات

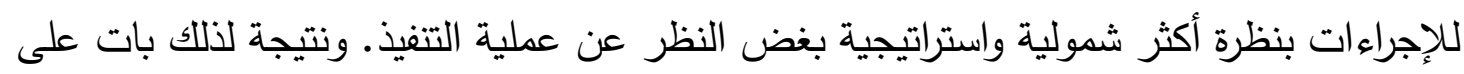

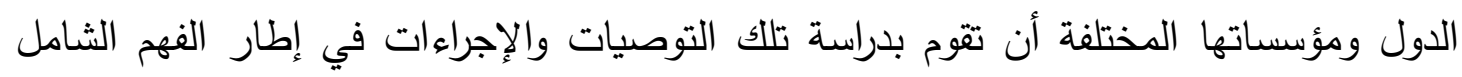

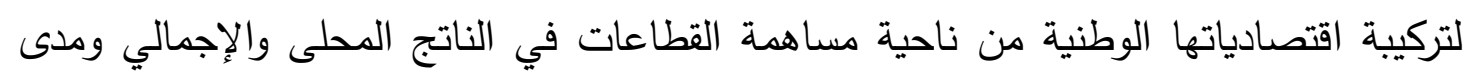

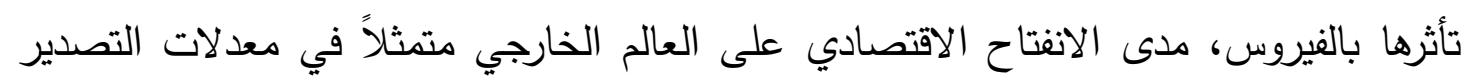

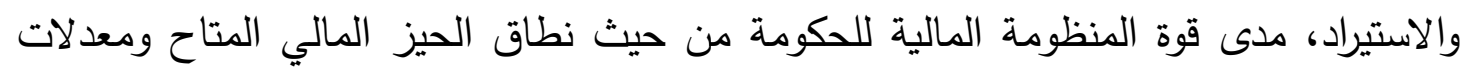

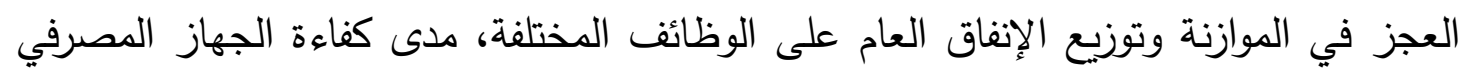

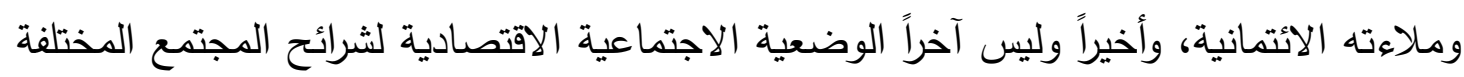
وبالأخص الأكثر تضرراً من انتشار الفيروس. فضلاً عن ذلك؛ لم تتطرق معظم التقارير إلى القضايا المتعلقة بالأثر طويل المدى على مجموعة

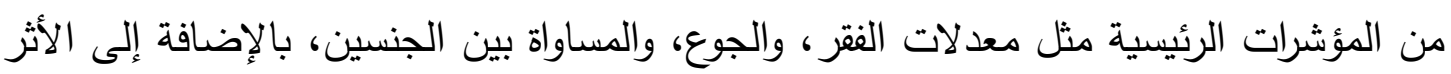

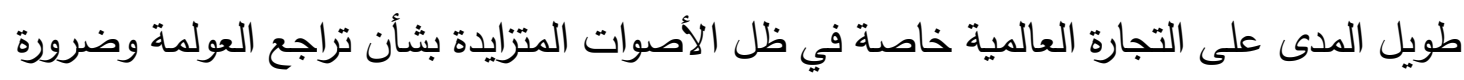

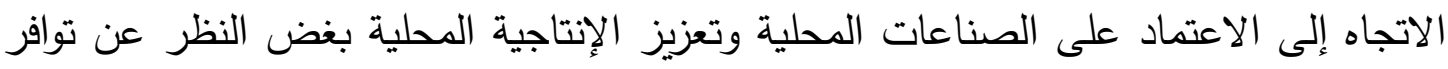

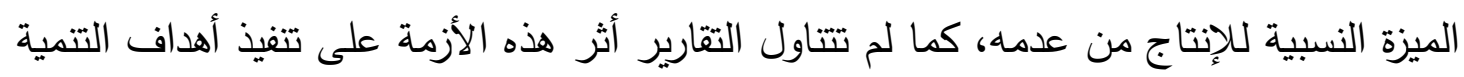

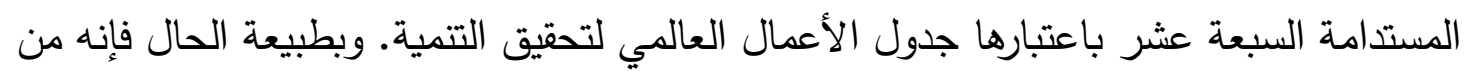

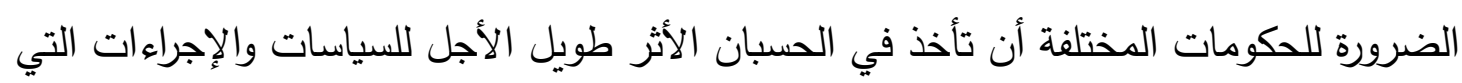

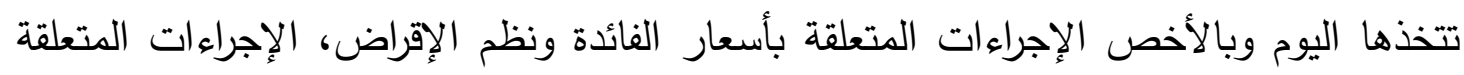

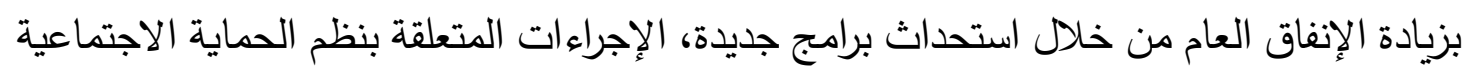

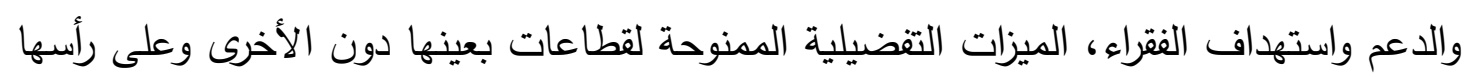

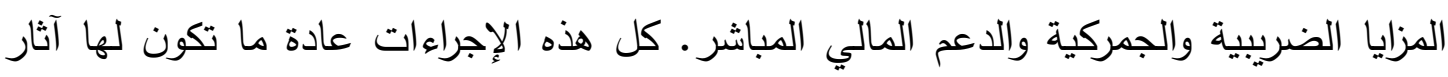
عميقة على الاقتصاد الوطني في الأجلين المتوسط والطويل.

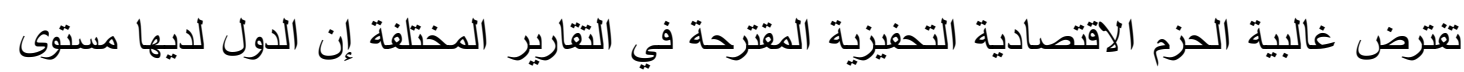
البنية التحتية المادية والبشرية التي يؤهلها لتنفيذ هذه السياسات والإجراءات بشكل كفيه لفئه وفعال. وبطبيعة الحال فليس هذا هو واقع الأمر وبالأخص في الدول النامية. وبالتالي فإن مدى فاعلية 
هذه الإجراءات في المساهمة في التعافي الجيد بعد الأزمة سوف يختلف من دولة إلى أخرى وفقاً

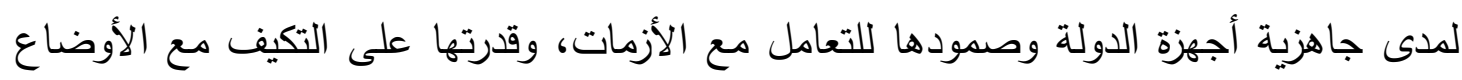

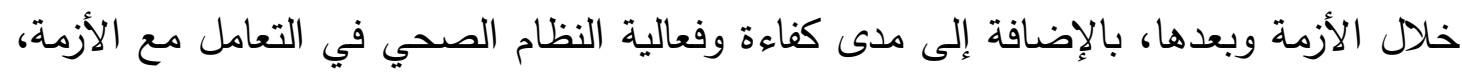
ومدى كفاءة الحكومة في الاتصال الجيد والثفافية في تقديم المعلومات الكافية للمواطنين والفئات المختلفة بما يعزز الثقة.

ولعلّ من الدروس المستفادة من هذه الأزمة للدولة المصرية هي ضرورة إعادة النظر في أولويات

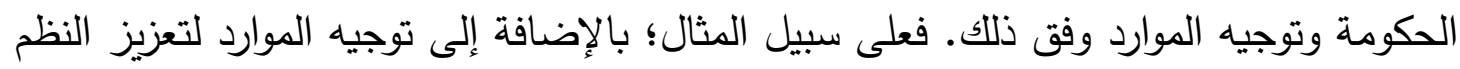

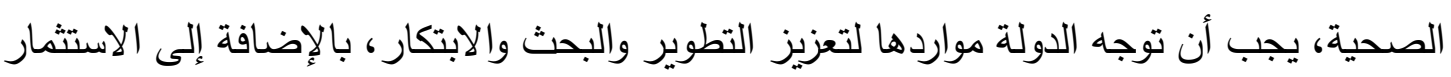
في النظم الوقائية لتعزيز جاهزية الأنظمة المختلفة لمواجهة الأزمات. ومن الجليّ أن الأزمة الحالية

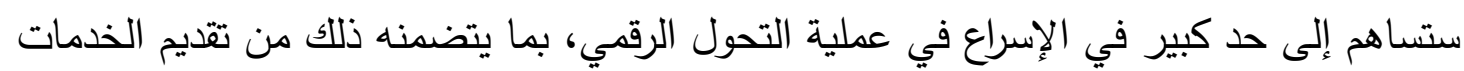

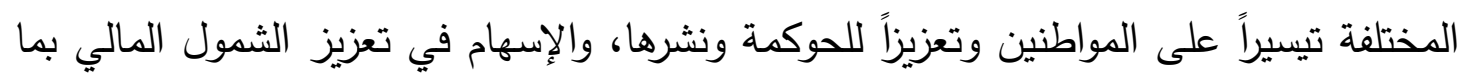

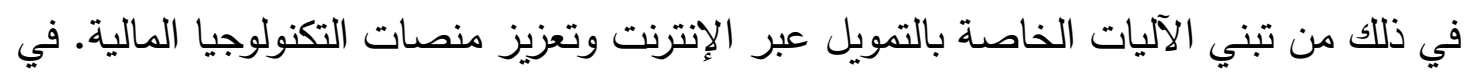
الوقت نفسه بات الاستثمار في شبكات الضمان الاجتماعي وقواعد البيانات الخاصة بها أمراً حتمياً للتعامل مع الأزمات في المستقبل بشكل فعال وذلك مع تطوير نظم إدارة الطوارئ والأزمات. ويجب أن تولي الدولة اهتماماً بعملية تشجيع الصناعة المحلية، ومساعدة المشروعات الصغيرة

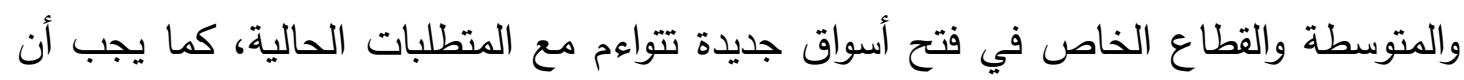

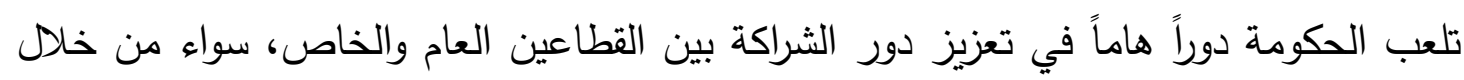

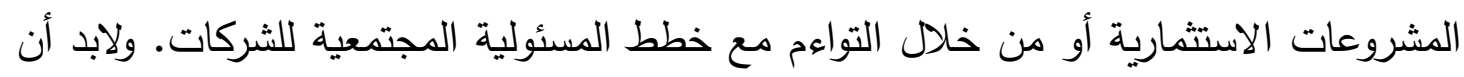

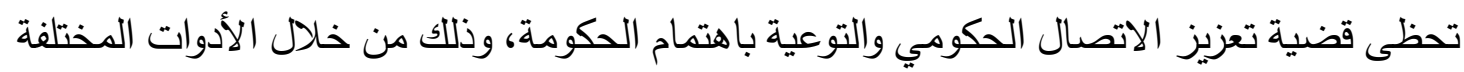

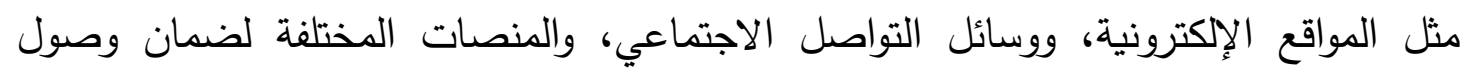

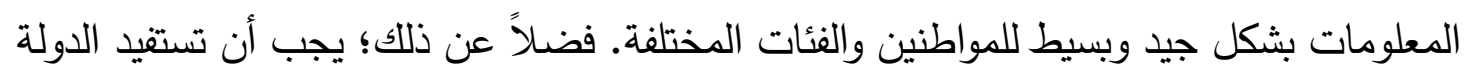
من الزخم الحالي المتعلق بقضية الديون ورفع العبء عن الدول المتضررة، وأن تعمل على إيجاد فرص لمبادلة الديون مع الدول المختلفة، بالإضافة إلى زيادة المساعدات الرئ الرسمية.

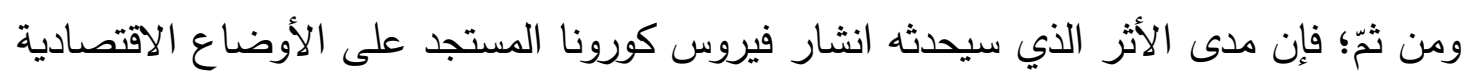

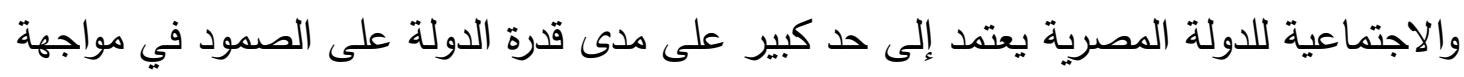

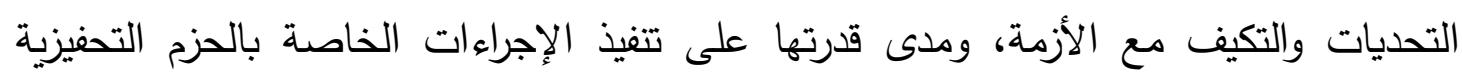

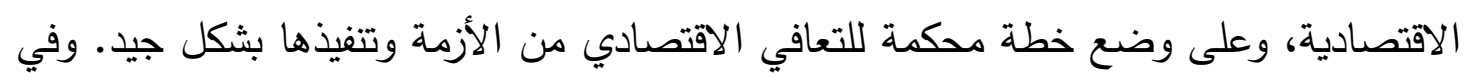

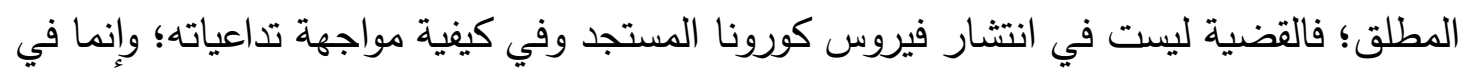

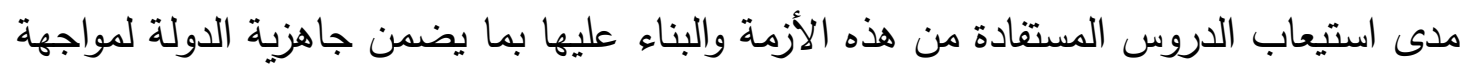

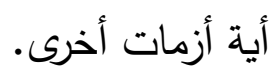




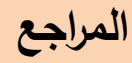

- IMF, "World Economic Outlook", April 2020, https://www.imf.org/ /media/Files/Publications/WEO/2020/April/ English/text.ashx?la=en

- IMF, "Policy Steps to Address the Corona Crisis", March 2020, https://www.google.com/url?sa=t\&rct=j\&q=\&esrc=s\&source=web $\& c d=2 \& c a d=r j a \& u a c t=8 \& v e d=2$ ahUKEwjP 8 KLOmaDpAhVW3I UKHT7KCakQFjABegQIAxAB\&url=https\%3A\%2F\%2Fwww.im f.org\%2F \%2Fmedia\%2FFiles\%2FPublications $\% 2$ FPP $\% 2 F 2020 \%$ 2FEnglish\%2FPPEA2020015.ashx\&usg=AOvVaw28iSpd_Lora1S woETLmkwH

- ILO, "ILO Monitor: COVID-19 and the World of Work", 7 April 2020 ,

https://www.ilo.org/wcmsp5/groups/public/@dgreports/@dcomm/ documents/briefingnote/wcms_740877.pdf

- African Union, "Impact of the Coronavirus (COVID-19) on the African Economy", 2020, https://www.tralac.org/documents/resources/covid-19/3218impact-of-the-coronavirus-covid-19-on-the-african-economyafrican-union-report-april-2020/file.html

- World Economic Forum, "Emerging Priorities and Principles for Managing the Global Economic Impact of COVID-19”, April 2020 , http://www3.weforum.org/docs/WEF_Chief_Economists_Outlook _April_2020.pdf

- World Bank East Asia and Pacific, "Part1: COVID-19 Impact and Response", April 2020, 
https://openknowledge.worldbank.org/bitstream/handle/10986/334 77/211565-ch01.pdf

- World Bank, "Proposed Sustainability Checklist for Assessing Economic Recovery Interventions", April 2020, http://pubdocs.worldbank.org/en/223671586803837686/Sustainabil ity-Checklist-for-Assessing-Economic-Recovery-InvestmentsApril-2020.pdf

صندوق النقد العربي، تقرير آفاق الاقتصاد العربي، (أبريل2020)، https://www.amf.org.ae/sites/default/files/aeo/2020/AEO_Apr_202 0_v2.pdf

- UNCTAD, " The Coronavirus shock: a story of another global crisis foretold and what policymakers should be doing about it", March 2020, https://unctad.org/en/PublicationsLibrary/gds_tdr2019_update_coro navirus.pdf

- UNCTAD, " Impact of the COVID-19 Pandemic on Global FDI and GVCs" https://openknowledge.worldbank.org/bitstream/handle/10986/334 77/211565-ch01.pdf, March 2020, https://unctad.org/en/PublicationsLibrary/diaeiainf2020d3_en.pdf

- IMF, "World Economic Outlook", April 2020, https://www.imf.org/ /media/Files/Publications/WEO/2020/April/ English/text.ashx?la=en

- United Nations, " Shared Responsibility, Global Solidarity: Responding to the socio-economic impacts of COVID-19", March 2020 ,

- https://unsdg.un.org/sites/default/files/2020-03/SG-Report-SocioEconomic-Impact-of-Covid19.pdf 
- United Nations, ESCAP, " The Impact and Policy Responses for COVID-19 in Asia and the Pacific", March 2020, https://www.unescap.org/sites/default/files/COVID\%20_Report_E SCAP.pdf

- FAO, " COVID-19 and the risk to food supply chains: How to respond?", March 2020, http://www.fao.org/3/ca8388en/CA8388EN.pdf

- IMF, " Global Financial Stability Report", April 2020, https://www.imf.org/ /media/Files/Publications/GFSR/2020/April/ English/text.ashx?la=en

- UNOCHA, " Global Humanitarian Response Plan: COVID -19", https://www.unocha.org/sites/unocha/files/Global-HumanitarianResponse-Plan-COVID-19.pdf

- UNCTAD, " The COVID- 19 shock to Developing Countries: Towards a "whatever it takes" program for the two thirds of the world's population being left behind", March 2020, https://unctad.org/en/PublicationsLibrary/gds_tdr2019_covid2_en. pdf 